\title{
Phytochemical studies and biological activity of three Chinese Schisandra species (Schisandra sphenanthera, Schisandra henryi and Schisandra rubriflora): current findings and future applications
}

\author{
Agnieszka Szopa $($ iD $\cdot$ Magda Barnaś $\cdot$ Halina Ekiert
}

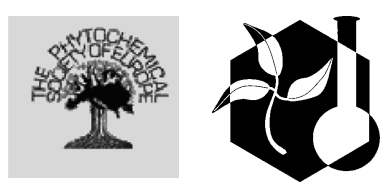

Received: 6 February 2018/Accepted: 15 June 2018/Published online: 3 October 2018

(C) The Author(s) 2018

\begin{abstract}
Schisandra chinensis (Chinese magnolia vine) is the best-known representative of the genus Schisandra, widely used in the official East-Asian, North American and European medicine. The article recalls the healing value of this species and, above all, presents the current state of knowledge on the chemical composition and biological activity of three other species of the Schisandra genus: Schisandra sphenanthera, Schisandra henryi and Schisandra rubriflora. In addition to dibenzocyclooctadiene lignans (the so-called 'Schisandra chinensis lignans'), they also contain other groups of lignans (e.g. 4aryltetralin, aryltetralone, tetrahydrofuran and
\end{abstract}

butane-type lignans) as the main compounds responsible for biological activity. The lignans are accompanied by other groups of compounds, including triterpenoids and nortriterpenoids. A review of biological studies, e.g. of empirically confirmed hepatoprotective, cytotoxic and anti-HIV-1 activities, proves that these species have a high therapeutic potential and may constitute a new East-Asian proposition for European medicine. The article also draws attention to the possibility of using the biosynthetic potential of the biomass from in vitro cultures of the described species and biotechnological solutions as an alternative to plant raw materials.
A. Szopa $(\bowtie) \cdot$ M. Barnaś $\cdot$ H. Ekiert

Chair and Department of Pharmaceutical Botany, Jagiellonian University, Medical College, Medyczna 9, 30-688 Kraków, Poland

e-mail: a.szopa@uj.edu.pl 


\section{Graphical abstract}

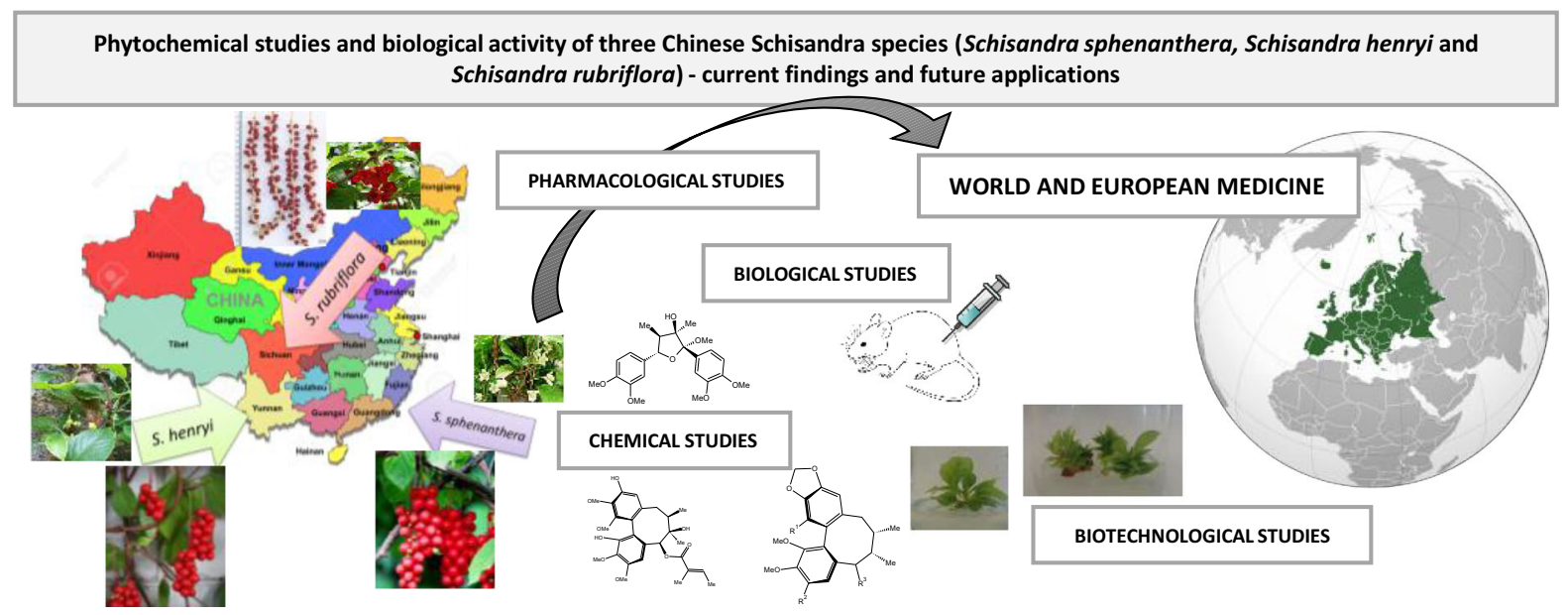

Keywords Schisandra lignans - Triterpenoids · Nortriterpenoids - Schisandra genus .

Nan wuweizi · Yi geng wuweizi ·

Hong hua wuweizi

\section{Introduction}

The genus Schisandra includes from 20 to 30 species (Hancke et al. 1999; Saunders 2000). The natural habitats of Schisandra species are located in East and South-East Asia, twelve of those species are endemic to China (Saunders 2000; Wu et al. 2008). The species of Schisandra differ from one another in small details in their morphological structure. The knowledge of the chemical composition of different parts of these species (leaves, stems, flowers, or fruits) is not satisfactory. Most of them are rooted in Traditional Chinese Medicine (TCM) as medicinal plants (Saunders 2000; Wu et al. 2008; Szopa et al. 2017a).

The best-known worldwide species from this genus is Schisandra chinensis Turcz. Baill.-Chinese magnolia vine. The knowledge of the valuable medicinal properties of Schisandra fruits (Bei-wuweizi, Northern magnolia vine fruit) is based on the Traditional Chinese Medicine (Fil'kin 1952; Bensky and Gamble 1993). Nowadays, monographs on Schisandra chinensis fruits are included in numerous pharmacopoeias, not only in Asian countries (China, Japan, South Korea and Russia) (Korea Food and Drug Administration
2002; Chinese Pharmacopoeia Commission 2005; Panossian and Wikman 2008), but also in countries of Europe (European Directorate for the Quality of Medicines 2017) and USA (Upton et al. 2011). Since 2007, they have also been accepted by International Pharmacopoeia edited by WHO (World Health Organization 2007) as medicinal plant raw material. Also, since 2010, the $S$. chinensis fruit has been accepted by the European Food Safety Authority (EFSA) as 'safe nutrition ingredients with tonic for the support of mental and well-being application' (European Food Safety Authority 2010). Moreover, S. chinensis is also recognized as a plausible anti-aging and skin conditioning cosmetics component in the database of the European Inventory of Cosmetic Ingredients (CosIng) (Szopa et al. 2016a).

Recently, we documented the state of the art about the progression of studies on $S$. chinensis in our review article (Szopa et al. 2017a). They deal with bioactive components, pharmacological properties, analytical and biotechnological researches.

Schisandra chinensis fruit extracts are used in medicine because of their valuable biological properties: hepatoprotective, adaptogenic and ergogenic, anti-cancer, anti-inflammatory, antiulcer, antioxidative and detoxifying (Szopa et al. 2017a). These activities are mainly driven by dibenzocyclooctadiene lignans, which are called, even in the professional scientific literature, 'Schisandra chinensis lignans' due to their complex, and at the same time unique, 
Table 1 The predominant dibenzocyclooctadiene lignans detected in the fruits of: S. chinensis, S. sphenanthera, S. henryi and $S$. rubriflora

\begin{tabular}{ll}
\hline Species & Dibenzocyclooctadiene lignans \\
\hline S. chinensis & $\begin{array}{c}\text { Schisandrin, schisandrins B and C, gomisins A and G, schisantherins A and B, deoxyschisandrin, } \gamma \text {-schisandrin, } \\
\text { schisanthenol }\end{array}$ \\
S. sphenanthera & $\begin{array}{r}\text { Gomisins: C, S, K3 and J, epigomisin O, 6-O-benzoylgomisin, benzoylgomisin U, methylgomisin, } \\
\text { tigloylgomisin P, angeloylgomisin P, schisantherins A-D, deoxyschisandrin, schisanhenol }\end{array}$ \\
S. henryi & $\begin{array}{l}\text { Schisantherins A and B, deoxyschisandrin, schisandrin, gomisin G, benzoylgomisin Q, isoanwulignan } \\
\text { S. rubriflora }\end{array}$ \\
$\begin{array}{l}\text { Gomisins B, C, G, J, N, O, Q, S and T, isogomisin O, schisandrin, schisandrin A, angeloylgomisins P and Q, } \\
\text { benzoylgomisin Q }\end{array}$ \\
\hline
\end{tabular}

structure (they are present mainly in the fruit, from 7.2 to $19.2 \%$ DW) (Opletal et al. 2004; World Health Organization 2007; Szopa et al. 2017a) (Table 1). The main source of this raw material in Europe and America are imports from Southeast Asia, primarily from China. The theoretically possible chemical synthesis of Schisandra lignans involves many stages and is very complicated. So far, only one synthetic drug is available-Bifendate (BDD, biphenyl dimethyl-dicarboxylate), manufactured in China, it is used in medicine as a hepatoprotective agent (Shuwei and Haodong 2000).

The majority of scientific work on other species of the genus Schisandra has been performed in China. Analysis of the reports shows that potential biological activities of other species from that genus are very probable.

The second in the order of $S$. chinensis species described in the literature as competing in terms of medical applications is $S$. sphenanthera Rehder \& E. H. Wilson (Nan-wuweizi, Southern magnolia vine fruit) (Huyke et al. 2007; Zhu et al. 2007; Lu and Chen 2009). However, the chemical compositions of the fruits of the two Schisandra species (Northern and Southern magnolia vines) are quite different ( $\mathrm{Lu}$ and Chen 2009). Since 2005, the fruits of these two plants have been recognized as two different raw materials, namely "bei wuweizi" (Fructus Schisandrae chinensis) and "nan wuweizi" (Fructus Schisandrae sphenantherae), respectively, by the Chinese Pharmacopoeia (Chinese Pharmacopoeia Commission 2005; Sun et al. 2010; Wei et al. 2010). On the other hand, the monograph on Schisandrae chinensis fruit has appeared in the European Pharmacopoeia since 2008 (European Directorate for the Quality of Medicines 2013). What is important is the fact that S. chinensis only was approved as a herbal remedy in
Europe and North America (World Health Organization 2007; Upton et al. 2011; European Directorate for the Quality of Medicines 2017). In its monographs, one can only find descriptions of morphological and chromatographic methods of distinguishing $S$. chinensis fruit against adulteration of the raw material with Schisandrae sphenantherae fructus.

Scientific research on the species of the genus Schisandra is prominent. Some studies have reported a high chemical and biological potential of $S$. henryi C.B. Clarke (翼梗五味子; yi geng wuweizi) and S. rubriflora (Franch.) Rehd. et Wils (红花五味子; hong hua wuweizi) (Wu et al. 2008). These species, along with $S$. sphenanthera, could be regarded as sources of valuable medicinal raw materials in Europe.

The major purpose of this review article is to gain the basic and new knowledge of chemical composition, biological activities and potential biotechnological solutions for providing industry with raw materials.

Importantly, the available databases contain only one review publication comparing the chemical composition of $S$. sphenanthera and $S$. chinensis (Lu and Chen 2009). Furthermore, there are no publications describing the current state of knowledge on the species $S$. henryi and S. rubriflora.

\section{Natural habitats and possibility of cultivation in Europe}

All species of Schisandra are scandent, i.e. climbing, woody vines; they lack tendrils or other specialized structures for climbing, but become entangled on supporting vegetation by spiral stem growth. All of the species have a very similar growth pattern, but 
small differences in the morphology of individual species are visible. The exact morphological and botanical differences of each Schisandra species were described by Saunders (2000).

All Schisandras occur naturally in East Asia, from Hokkaido (Japan) and Far Eastern Siberia in the north-east, to Java and Bali in the south, and to Uttar Pradesh (India) in the west. The centre of diversity lies in south-eastern and south-central China. However, there are considerable differences between the spread of individual species. Moreover, one species - Schisandra glabra, has natural habitats in North America (Panero and Aranda 1998; Denk and Oh 2005).

Schisandra sphenanthera is a species endemic to China; it occurs naturally in central and southern provinces of China: Anhui, Gansu, Guizhou, Henan, Hubei, Hunan, Jiangsu, Shaanxi, Shanxi, Sichuan, Yunnan, and Zhejiang. This plant has the growth habit of a woody vine, apparently dioecious (but probably monoecious). Leaf laminas are $5.5-11 \mathrm{~cm}$ long and $2.5-6 \mathrm{~cm}$ wide, elliptic to ovate. The flowers borne in axils of fugacious bracts at the base of young shoots are solitary with variably yellow, orange, or red tepals (6-8 male flowers, and 5-8 female flowers). The male flowers have an androecium composed of 15-23 essentially free stamens. The gynoecium of female flowers has $25-45$ free carpels. Fruit peduncles are glabrous, 3-6.5 $\mathrm{cm}$ long. The fruits are red, 5-9 $\mathrm{mm}$ long and 4-8 $\mathrm{mm}$ wide, with 1-2 discoid to flattened-reniform seeds (Saunders 2000; Lu and Chen 2009).

Schisandra henryi has its natural habitat in China in the province of Yunnan, especially in the southeast mountains. It is a woody vine, apparently dioecious (but probably monoecious). Lateral branches are narrow, with variably persistent perules at the base. The leaf laminas are 7.5-11.5 cm long and 4.5$7.5 \mathrm{~cm}$ wide, with an elliptic to ovate shape. Flowers borne in axils of (semi-)persistent perules at the base of young shoots or in axils of leaves are solitary, with yellow or orange tepals (6-10 male flowers and 6-8 female flowers). Male flowers have an androecium with 12-46 essentially free stamens, and the female flowers have a gynoecium with 28-65 free carpels. Fruit peduncles are glabrous, elongated $(6-10 \mathrm{~cm})$. The fruits are red, 4.5-8.5 mm long and 3.5-6.5 mm wide, with 1-2 seeds (discoid to flattened-reniform, rarely flattened-pyriform) (Saunders 2000).
Schisandra rubriflora occurs naturally only in the western Sichuan province of China. Its growth habit is that of a woody vine, apparently dioecious (but probably monoecious). Lateral branches are lacking wings, and have fugacious perules at the base. The leaf laminas are 7-11.5 cm long and $2.5-5.5 \mathrm{~cm}$ wide, glabrous, elliptic to obovate-elliptic. The flowers are solitary and borne in axils of fugacious bracts at the base of young shoots. The tepals are deep (purple-)red and glabrous (6-9 male flowers, and 6-7 female flowers). The male flowers have an androecium of 34-66 essentially free stamens spirally arranged around the floral axis, while the female flowers have a gynoecium of 50-70 free carpels. The fruit peduncles are glabrous, elongated, from 5 to $7 \mathrm{~cm}$ long, The fruits are dark (purple-)red, 5-8 mm long and 4-7 $\mathrm{mm}$ wide. The seeds are discoid to flattened-reniform, 1-2 per apocarp (Saunders 2000).

Cropping of Schisandra species outside of the East Asian area is difficult but possible. There are reports of successes in cultivation in moderate climates in Europe and America. The main problem with the cultivation of the species is related to the low frost resistance of these plants. However, adequate winter protection can ensure good growth of the climbing plants. In addition, there are too few horticultural reports on the optimal conditions for growing Schisandra outside of the natural habitats. This is mainly due to the low popularity of these species, as they are known only as ornamental plants, planted in gardens and parks. In Poland, the only distributor of the species $S$. rubriflora and $S$. henryi is the private nursery 'Clematis' (http://www.clematis.com.pl/).

\section{Schisandra lignans-classification, biosynthetic and chemical characterization}

\section{Classification of lignans in the plant kingdom}

The Schisandra fruits are characterized by a rich, still not fully known, chemical composition. The most important constituents are lignans (Umezawa 2003; Opletal et al. 2004). There are different classifications of these compounds. Lignans are classified based on the way in which oxygen is incorporated into the skeleton and the cyclization pattern into eight subgroups: furofuran, furan, dibenzylbutane, dibenzylbutyrolactone, aryltetralin, arylnaphthalene, 
dibenzocyclooctadiene and dibenzylbutyrolactol (Whiting 1985, 1990). Another, often assumed classification, based on chemical structures, divided lignans into five classes: dibenzocyclooctadiene lignans (type A), spirobenzofuranoid dibenzocyclooctadiene lignans (type B), 4-aryltetralin lignans (type C), 2,3-dimethyl1,4-diarylbutane lignans (type D), and 2,5-diaryltetrahydrofuran lignans (type E) (Lu and Chen 2009).

Lignans are plant secondary metabolites of not fully known biosynthetic pathways (Gottlieb 1972; Umezawa 2003). The most-accepted biosynthetic pathway is considered to be the one that leads from the conversion: coniferyl alcohol $\rightarrow$ pinoresinol (furofuran) $\rightarrow$ lariciresinol (furan) $\rightarrow$ secoisolariciresinol (dibenzylbutane) $\rightarrow$ matairesinol (dibenzylbutyrolactone) (Umezawa 2003). But lignans without 9(9')oxygen, like dibenzocyclooctadiene, dibenzylbutane and furan lignans without oxygen at $\mathrm{C} 9$ and $\mathrm{C}^{\prime}$, may be formed by a coupling of propenylphenols such as isoeugenol (Gottlieb 1972).

\section{Schisandra lignans}

The most common, for the genus Schisandra, subgroup of lignans is that of dibenzocyclooctadiene lignans, and for this reason they are often, even in scientific elaborations, called 'Schisandra lignans', or 'Schisandrae chinensis lignans'. The first Schisandra lignan was isolated by Kochetkov et al. (1961). Currently, approximately 150 lignan derivatives with the dibenzocyclooctadiene skeleton have been isolated from plants of the Schisandraceae family (Ren et al. 2010). Moreover, the naturally occurring lignans have been found to exist exclusively as one enantiomer or as enantiomeric mixtures with various enantiomeric compositions. These compounds can be further categorized, based on their stereostructures, into S- or R-biphenyl configuration groups. Structural elucidation is possible by the use of spectroscopic techniques, including ultraviolet (UV), infrared (IR), mass (MS), nuclear magnetic resonance (NMR), and circular dichroism (CD) spectra, as well as advanced 2D NMR (Opletal et al. 2004).

The dibenzocyclooctadiene-type lignans are very characteristic for $S$. chinensis, in which they are the main component of fruit extracts (World Health Organization 2007). The main compounds of this group are: schisandrin, schisandrin $\mathrm{C}$, gomisin $\mathrm{A}$ and $\mathrm{G}$, schisantherin $\mathrm{A}$ and $\mathrm{B}$, deoxyschisandrin, $\gamma$ - schisandrin and schisanthenol (Table 1). The remaining species are characterized by the presence of still other subgroups/types of lignans. This fact is a challenge in many phytochemical studies whose aim is to obtain the best knowledge of the qualitative and quantitative composition of other Schisandra species. This is an important issue in order to provide a useful reference for good quality control of Schisandra fruits. The analyses use the most modern spectrophotometric and chromatographic methods, including thin-layer chromatography (TLC), high-performance liquid chromatography (HPLC), liquid chromatography-mass spectrometry (LC-MS and LC-ESI-MS), capillary electrophoresis (CE) and capillary electrochromatography (CEC) (Chang et al. 2005; Shi et al. 2009).

\section{Biological activities}

Biological activity of lignans is a frequent object of work in the field of pharmacological studies on the Schisandra genus (Table 2). The most studied group of lignans is that of dibenzocyclooctadiene lignans. Their biological activity is very valuable and determined individually for separate compounds.

Scientific research has confirmed the hepatoprotective and detoxifying properties of lignans for the liver parenchyma, and also their valuable antioxidant properties. Dibenzocyclooctadiene lignans also show immunostimulatory and adaptogenic effects, as well as antiviral and antibacterial effects. As demonstrated by studies, dibenzocyclooctadiene lignans also have protective effects on the myocardium and properties stimulating the uterine muscle. Moreover, previous studies have confirmed their beneficial effects on the central nervous system by protecting nerve cells from dying and increasing the concentration of neurotransmitters (Hernandez et al. 1988; Lu and Liu 1991; Yasukawa et al. 1992; Hancke et al. 1994; Ko et al. 1995; World Health Organization 2007; Hwang et al. 2009, 2011; Miao et al. 2009; Xiao et al. 2010c; Chiu et al. 2011; Waiwut et al. 2012; Chen et al. 2012; Casarin et al. 2014; Hu et al. 2014; Wang et al. 2015; Thandavarayan et al. 2015; Szopa et al. 2016a, 2017a). Detailed directions of the biological activity of dibenzocyclooctadiene lignans are presented in Table 2. 
Table 2 Bioactivity of dibenzocyclooctadiene lignans supported by scientific studies

\begin{tabular}{|c|c|c|c|}
\hline Action profile & $\begin{array}{l}\text { Active ingredient } \\
\text { showing biological } \\
\text { activity }\end{array}$ & Mechanism of action & References \\
\hline \multirow[t]{7}{*}{$\begin{array}{l}\text { Hepatoprotective } \\
\text { effect }\end{array}$} & \multirow[t]{4}{*}{ Gomisin A } & $\begin{array}{l}\text { Stimulation of glutathione reductase activity and } \\
\text { reduction of too high levels of ALAT and ASPAT }\end{array}$ & \multirow[t]{4}{*}{ Ko et al. (1995) } \\
\hline & & $\begin{array}{l}\text { Increase in the activity of cytochrome B5, P450, } \\
\text { NADPH, cytochrome C reductase, aminophenazone } N \text { - } \\
\text { demethylase and } O \text {-deetylase- } 7 \text {-ethoxycoumarin }\end{array}$ & \\
\hline & & $\begin{array}{l}\text { Reduction in the activity of 3-4-dibenzopyrene } \\
\text { hydroxylase }\end{array}$ & \\
\hline & & Acceleration of hepatocyte proliferation & \\
\hline & \multirow[t]{3}{*}{$\gamma$-schisandrin } & $\begin{array}{l}\text { Increase in the concentration of mitochondrial } \\
\text { glutathione }\end{array}$ & \multirow[t]{3}{*}{$\begin{array}{l}\text { Lu and Liu (1991) and Ko } \\
\text { et al. (1995) }\end{array}$} \\
\hline & & Increase in vitamin $\mathrm{C}$ in the liver & \\
\hline & & Reduction in the affinity of aflatoxins to DNA & \\
\hline \multirow{3}{*}{$\begin{array}{l}\text { Ergogenic and } \\
\text { adaptogenic } \\
\text { effects }\end{array}$} & \multirow{3}{*}{$\begin{array}{l}\text { Dibenzocyclooctadiene } \\
\text { lignans in general }\end{array}$} & Reduction in tiredness & \multirow{3}{*}{$\begin{array}{l}\text { Hancke et al. (1994) and } \\
\text { Chen et al. (2012) }\end{array}$} \\
\hline & & $\begin{array}{l}\text { Improvement in bodily function, increase in physical } \\
\text { and mental endurance }\end{array}$ & \\
\hline & & Improvement in visual acuity at dusk & \\
\hline \multirow{2}{*}{$\begin{array}{l}\text { Anti- } \\
\text { inflammatory } \\
\text { effect }\end{array}$} & \multirow[t]{2}{*}{$\begin{array}{l}\text { Gomisin } \mathrm{A} \text {, gomisin } \mathrm{J} \\
\text { schisandrin } \mathrm{C}\end{array}$} & $\begin{array}{l}\text { Reduction of inflammation by inhibiting the expression } \\
\text { of nitric oxide and production of prostaglandins }\end{array}$ & \multirow{2}{*}{$\begin{array}{l}\text { World Health Organization } \\
\text { (2007) and } \mathrm{Hu} \text { et al. } \\
\text { (2014) }\end{array}$} \\
\hline & & Induction of cyclooxygenase 2 release & \\
\hline \multirow[t]{2}{*}{ Antiulcer activity } & \multirow[t]{2}{*}{$\begin{array}{l}\text { Dibenzocyclooctadiene } \\
\text { lignans in general }\end{array}$} & $\begin{array}{l}\text { Reduction in peptic ulcer symptoms after consumption } \\
\text { of ethanolic extracts from } S \text {. chinensis fruit }\end{array}$ & \multirow{2}{*}{$\begin{array}{l}\text { Hernandez et al. (1988) and } \\
\text { World Health } \\
\text { Organization (2007) }\end{array}$} \\
\hline & & Accelerated regeneration of ulcer wounds & \\
\hline \multirow{4}{*}{$\begin{array}{l}\text { Antioxidant and } \\
\text { detoxification } \\
\text { effects }\end{array}$} & \multirow{4}{*}{$\begin{array}{l}\text { Schisandrin, schisandrin } \\
\text { B and C }\end{array}$} & Inhibition of microsomal lipid peroxidation & \multirow{4}{*}{$\begin{array}{l}\text { Miao et al. (2009), Chiu } \\
\text { et al. (2011) and } \\
\text { Thandavarayan et al. } \\
\text { (2015) }\end{array}$} \\
\hline & & $\begin{array}{l}\text { Reduction in the amount of superoxide free radicals in } \\
\text { neutrophils }\end{array}$ & \\
\hline & & $\begin{array}{l}\text { Reduction in the release of ALAT and lactate } \\
\text { dehydrogenase, which increases the viability of } \\
\text { hepatocytes }\end{array}$ & \\
\hline & & Increase in hepatic glutathione & \\
\hline \multirow[t]{5}{*}{$\begin{array}{l}\text { Anti-tumour } \\
\text { effect }\end{array}$} & \multirow[t]{5}{*}{$\begin{array}{l}\text { Gomisin } \mathrm{A} \text { and } \mathrm{N}, \\
\gamma \text {-schisandrin }\end{array}$} & $\begin{array}{l}\text { Inhibition of tumour marker production in hepatocytes } \\
\text { (glutathione S-transferase, GST-P) }\end{array}$ & \multirow{5}{*}{$\begin{array}{l}\text { Hwang et al. }(2009,2011) \text {, } \\
\text { Waiwut et al. }(2012) \text { and } \\
\text { Casarin et al. (2014) }\end{array}$} \\
\hline & & Reduction in tumour lesions in the liver & \\
\hline & & $\begin{array}{l}\text { Inhibition of the development of skin tumours and the } \\
\text { Papilloma virus }\end{array}$ & \\
\hline & & $\begin{array}{l}\text { Prevention of cell apoptosis through the production of } \\
\text { heat shock proteins- }-\mathrm{Hps} 70\end{array}$ & \\
\hline & & Induction of tumour cell apoptosis & \\
\hline \multirow[t]{3}{*}{ Antiviral activity } & \multirow{3}{*}{$\begin{array}{l}\text { Gomisin } \mathrm{A} \text { and } \mathrm{N}, \gamma- \\
\text { schisandrin, } \\
\text { schisanhenol } \\
\text { derivatives }\end{array}$} & Inhibition of the multiplication of the HIV virus & \multirow{3}{*}{$\begin{array}{l}\text { Yasukawa et al. (1992), } \\
\text { Xiao et al. (2010c) and } \\
\text { Wang et al. (2015) }\end{array}$} \\
\hline & & Inhibition of the multiplication of the Papilloma virus & \\
\hline & & $\begin{array}{l}\text { Inhibition of the multiplication of the tobacco mosaic } \\
\text { virus }\end{array}$ & \\
\hline
\end{tabular}




\section{Schisandra triterpenoids}

Classification, biosynthetic and chemical characterization

The second specific group of Schisandra secondary metabolites are Schisandra triterpenoids. Recently, numerous studies on this genus have concentrated on just this group of compounds. Generally, the triterpenoids from the Schisandraceae family can be classified into three groups, also according to their different carbon frameworks: lanostane (A), cycloartane (B), and Schisandra nortriterpenoids (C) (Xiao et al. 2008a). Schisandra nortriterpenoids is a unique group of metabolites because of their chemical structure, which is rarely found in the plant kingdom, namely being highly oxygenated with different lactone skeletons. Moreover, the Schisandra nortriterpenoids may be further grouped into different classes including the schisanartane, schiartane, 18-norschiartane, 18(13/14)-abeo-schiartane, preschisanartane and wuweiziartane types (Xiao et al. 2010a). A comprehensive review concentrated on Schisandra triterpenoids was published in Xiao et al. (2008a). The researchers also proposed a likely biosynthetic pathway of this group of secondary metabolites. A possible biosynthetic pathway could start from compounds of the cycloartane skeletonschizandronic acid, from which ring expansion, 3,4oxidative cleavage, oxidation and decarboxylation at C-28 and epoxidation finally lead to the formation of a typical schiartane skeleton-micrandilactone B. Next, the authors suppose that micrandilactone B is a precursor of various biosynthetic pathways for the separate types of Schisandra nortriterpenoids (Huang et al. 2008; Xiao et al. 2008a).

Their work has resulted in the identification of over 100 bioactive nortriterpenoids (Peng et al. 2015). Extensive investigations of this group of Schisandra metabolites have been conducted, especially by Sun and co-workers (Xiao et al. 2006b, 2007c, 2008b; Xue et al. 2010; Shi et al. 2011; Zhou et al. 2011).

\section{Biological properties}

Based on the latest studies, this group is growing as a result of finding and identifying new Schisandra triterpenoids. Their structure is very unusual and thus potentially biosynthetically unique, and they may therefore exhibit potentially significant bioactivities. Additionally, a large number of these compounds possess lactone structures, famous in the plant kingdom as compounds with significant biological activity. That is the reason why chemical studies are often coupled with biological ones (Connolly and Hill 2010).

In recent years, considerable efforts of researchers have been devoted to the discovery of anti-HIVbioactivity of triterpenoids from the genus Schisandra (Xiao et al. 2007c). The anti-HIV activity was shown for sphenalactones A-D (Xiao et al. 2007b) and sphenadilactone $\mathrm{C}$ ( $\mathrm{Li}$ et al. 2008).

Schinalactones B and C show significant cytotoxicity activity against PANC-1 cell lines (He et al. 2010), and sphenalactones A-D show low cytotoxicity activity against C8166 cells (Xiao et al. 2007c).

\section{Specific chemical composition}

\section{Schisandra sphenanthera}

Schisandra sphenanthera is the second popular species of the Schisandra genus, after S. chinensis. This is the reason for the largest number of scientific studies on the composition and biological activity of this species. Chemical analyses are conducted on different plant organs including fruits, stems, leaves and roots. Analyses of the chemical composition of the fruits of $S$. sphenanthera have revealed considerable differences in their composition in comparison with the fruits of $S$. chinensis. The dibenzocyclooctadiene lignans are the dominant group of secondary metabolites in $S$. sphenanthera fruit extracts; they have been found to contain compounds such as: pregomisin, gomisins: $\mathrm{C}, \mathrm{S}, \mathrm{K} 3, \mathrm{~J}$ and $\mathrm{U}$, epigomisin $\mathrm{O}$, 6-O-benzoylgomisin, benzoylgomisin $\mathrm{U}$, methylgomisin, tigloylgomisin $\mathrm{P}$, angeloylgomisin $\mathrm{P}$, schisantherins A-D, deoxyschisandrin, schisanthenol, and isoschisandrin. Derivatives of dibenzocyclooctadiene lignans have also been detected in the fruits, i.e. C18-dibenzocyclooctadiene lignans-schisphenins C-G (Fig. 1) and 6,7-seco-dibenzocyclooctadiene lignan—schisphenone (Fig. 2) (Huang et al. 2011). Moreover, other groups of lignans are also present in the S. sphenanthera fruit (Zhu et al. 2007; Ren et al. 2010; Huang et al. 2011; Liu et al. 2012; Chen et al. 


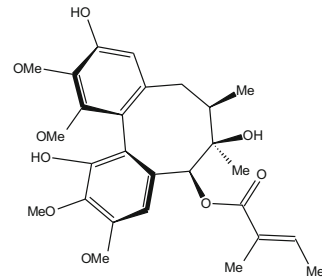

Schisphenin C

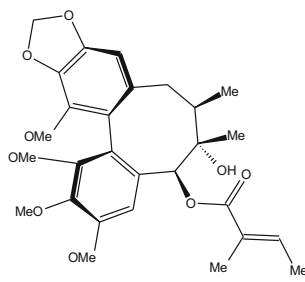

Schisphenin D

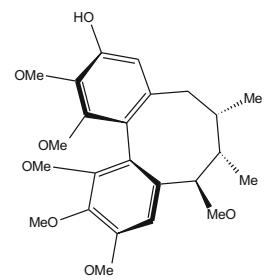

Schisphenin E

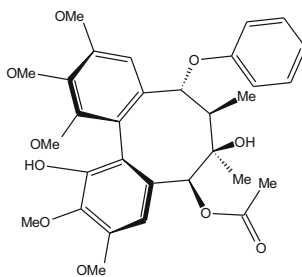

Schisphenin F

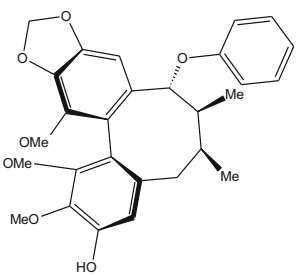

Schisphenin G

Fig. 1 Chemical structures of derivatives of C18-dibenzocyclooctadienes lignans characterisitic for $S$. sphenanthera: schisphenins $\mathrm{C}-\mathrm{G}$<smiles>COc1cc(CO)c(-c2c(C[C@H](C)C(C)=O)cc3c(c2OC)OCO3)c(OC)c1OC</smiles>

Fig. 2 Chemical structure of derivative of 6,7-seco-dibenzocyclooctadiene lignan isolated from $S$. sphenantheraschisphenone

2013). The confirmed ones include: 4-aryltetralin lignans (schisandrone), aryltetralone lignans (schisphentetralone A), 2,3-dimethyl-1,4-diarylbutane lignans (D,L-anwulignan, (+)-anwulignan, and sphenanlignan), and three 2,5-diaryltetrahydrofuran lignans (chicanine, D-epigalbacine, and ganschisandrine) (Lu and Chen 2009; Huang et al. 2011).

Analyses of the composition of the stems of $S$. sphenanthera have proved the existence, in addition to those previously known, of: gomisins B, G and O, epigomisin $\mathrm{O}$, schisantherin $\mathrm{A}$ and $\mathrm{D}$, marlignan $\mathrm{E}$ and angeloylgomisin $\mathrm{Q}$, and also new dibenzocyclooctadiene lignans-schisphenlignans A-D (Fig. 3) (Liang et al. 2013). Moreover, the roots of $S$. sphenanthera have been used to isolate and identify butane-type lignans, besides the known ones, such as: schiglaucins $\mathrm{A}$ and $\mathrm{B}$, epoxyzuonin, talaumidin, myristargenol A, and also eight previously unknown tetrahydrofuran lignans (Jiang et al. 2015).

In addition to lignans, triterpenoids have been isolated from $S$. sphenanthera fruits and identified as: schizandronic acid (ganwuweizic acid), anwuweizic acid, kadsuric acid, coccinic acid, schinalactones A$\mathrm{C}$ and $\mathrm{G}$ and schisanol (Lu and Chen 2009; Ren et al. 2009; He et al. 2010; Huang et al. 2011). Fruits of $S$. sphenanthera are also a source of highly oxygenated nortriterpenoids: sphenalactones A-D and sphenadilactone C and sphenasin A (Fig. 4) (Xiao et al. 2007c; Connolly and Hill 2010).

\section{Schisandra henryi}

In the available databases, very little information could be found on detailed phytochemical analyses of $S$. henryi. The research work has focused on analyzing the chemical composition of the shoots and leaves of $S$. henryi plants. Coexistence of as many as three groups of lignans has been confirmed in $S$. henryi: dibenzocyclooctadiene lignans, tetrahydrofuran lignans and tetralin lignans (Liu et al. 1988; Li et al. 2004c; Iu et al. 2009; Christophe 2013). The dibenzocyclooctadiene lignans occurring in $S$. henryi include: schisantherin A and B, deoxyschisandrin, schisandrin, gomisin G, benzoylgomisin $Q$ and isoanwulignan.

Studies on the chemical composition of the leaves of male $S$. henryi specimens grown in Poland have been confirmed by our own research. Analyses by the LC-DAD and UHPLC-MS/MS methods confirmed the presence of compounds from the three groups of lignans: dibenzocyclooctadiene lignans (schisantherin E, schisandrin, gomisin $\mathrm{G}$, angeloylgomisin $\mathrm{Q}$, benzoylgomisin $\mathrm{Q}$, schisantherin A, schisantherin $\mathrm{B}$, gomisin F, deoxyschisandrin, schisandrin C, angeloylgomisin $\mathrm{O}$, and schisantherin $\mathrm{D}$ ), aryltetralin lignans (wulignan $\mathrm{A} 1$ and $\mathrm{A} 2$, epiwulignan $\mathrm{A} 1$, 


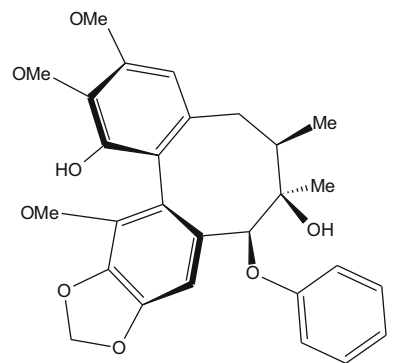

Schispheninlignan A

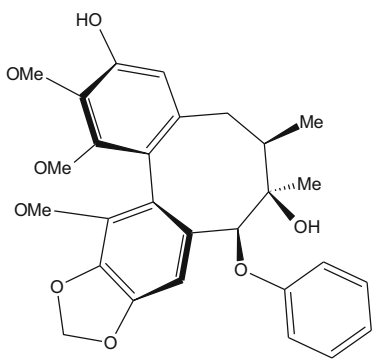

Schispheninlignan B

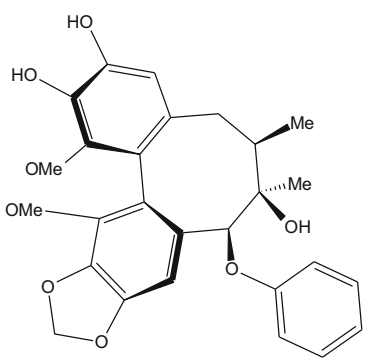

Schispheninlignan C

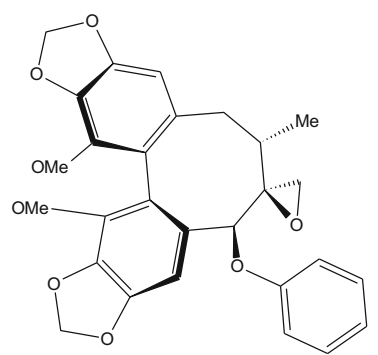

Schispheninlignan D

Fig. 3 Chemical structure of newly isolated from stems of S. sphenanthera dibenzocyclooctadiene lignans-schisphenlignans A-D

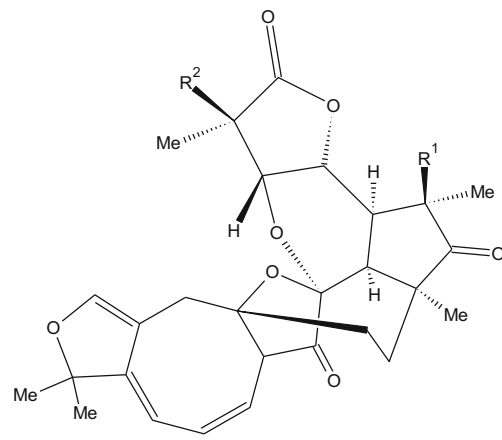

Sphenelactone A

Sphenelactone B

Sphenelactone C

Sphenelactone D

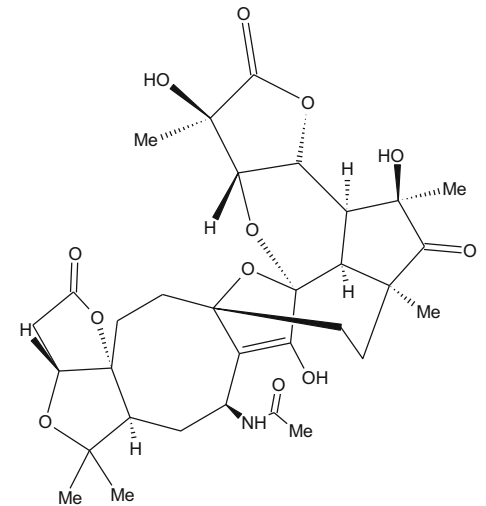

Sphenedilactone C

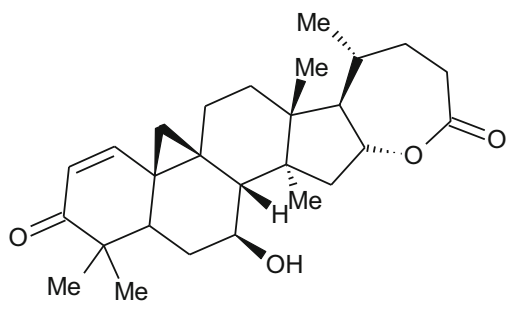

Sphenasin A

Fig. 4 Chemical structure of highly oxygenanted nortriterpenoids isolated from $S$. sphenanthera: sphenalactones A-D, sphlenadilactone $\mathrm{C}$ and sphenasin $\mathrm{A}$

enshicine, and epienshicine) and tetrahydrofuran lignans (henricine B) [unpublished].

The tetrahydrofuran lignans estimated only in $S$. henryi stems are: ganschisandrin, wulignans A1 and A2, epiwulignan A and epischisandron. Moreover, in $S$. henryi, two lignans from this group have been identified as unique to this species: henricine A and B (Fig. 5) (Iu et al. 2009).

From the group of tetralin lignans, only one compound has been identified in S. henryi shootsenshicine (Fig. 6) (Liu et al. 1984, 1988; Chen et al. 2003).

The second characteristic group of secondary metabolites found in $S$. henryi are triterpenoids: henrischinins A, B and C (identified only in leaves and shoots), kadsuric acid, nigranoic acid, isoschisandrolic acid, and schisandrolic acid. In addition, unique nortriterpenoid compounds have also been identified in the shoots, such as: henridilactones: A, B, C and D (Fig. 7) (Chen et al. 2003, 2010; Li et al. 2004c).

\section{Schisandra rubriflora}

From the available literature, it is known that dibenzocyclooctadiene lignans occur in the S. rubriflora species (Li et al. 2004b, 2008; Mu et al. 2011). Previous studies (from 1985) had indicated the 


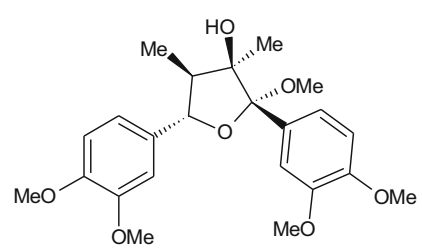

Henricine A

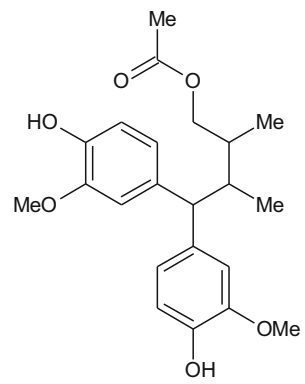

Henricine B
Fig. 5 Tetrahydrofuran lignans specific for S. henryi: henricine $\mathrm{A}$ and $\mathrm{B}$

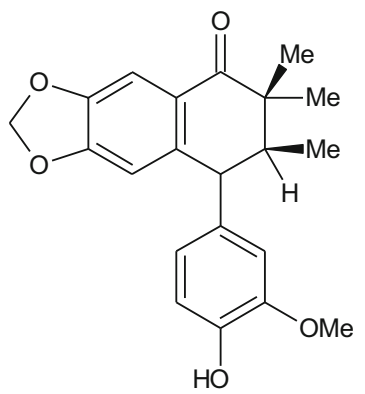

Enshicine

Fig. 6 Chemical structure of specific for $S$. henryi tetraline lignan-enshicine

occurrence of lignans characteristic of the Schisandra genus, such as: schisandrin, schisandrin $\mathrm{C}$, deoxyschisandrin, schisanthenol, schisanthenol B, schisantherin $\mathrm{B}$, gomisin $\mathrm{J}$ and $\mathrm{O}$, pregomisin and meso-dihydroguaiaretic acid (Wang and Chen 1985).

Based on more recent studies, S. rubriflora fruit extracts have been found to contain unique lignans (e. g. rubrilignans) as well as other lignans, both those known from the Schisandra genus such as gomisins $\mathrm{B}, \mathrm{C}, \mathrm{G}, \mathrm{J}, \mathrm{N}, \mathrm{O}, \mathrm{Q}, \mathrm{S}$ and $\mathrm{T}$, isogomisin $\mathrm{O},(+)-$ gomisin $\mathrm{K}$, schisandrin, schisandrin $\mathrm{A}$, angeloylgomisin $\mathrm{P}$ and $\mathrm{Q}$, benzoylgomisin $\mathrm{Q}$, and those lesserknown/rare ones such as wilsonilignan $\mathrm{C}$, marlignans $\mathrm{G}$ and $\mathrm{L}$, epiwulignan $\mathrm{A} 1$, wulignan $\mathrm{A} 2$, (Xiao et al. 2010b; Mu et al. 2011). What is important and noteworthy is that the fruit of S. rubriflora contains derivatives of dibenzocyclooctadiene lignans that are specific to this plant: rubrilignan $\mathrm{A}$ and $\mathrm{B}$, and rubschisantherin (Fig. 8) (Li et al. 2004a; Chen et al. 2006; $\mathrm{Mu}$ et al. 2011).

The stems of $S$. rubriflora were confirmed to contain also other specific dibenzocyclooctadiene lignans: rubrisandrin A and B (Fig. 8) and schirubrisins A-D (Fig. 9), together with the known ones: schisandrin, schisantherin A, angeloylgomisin Q and $\mathrm{P}$, tigloylgomisin $\mathrm{P}$, epigomisin $\mathrm{O}$, interiotherin $\mathrm{B}$, gomisin $\mathrm{D}$, benzoylgomisin $\mathrm{Q}, 6 \beta$-hydroxy-schisandrin A, 12-demethylwuweilignan I and machilin D (Li et al. 2008).

Moreover, the leaves and stems have been confirmed to contain the uncommon structures of dibenzocyclooctadiene lignans such as: meso-dihydroguaiaretic acid, meso-mono-methyl dihydroguaiaretic acid, 4,4'-(2R,3S)2,3-dimethylbutane-1,4-diyl)bis(1,2-dimethoxybenzene), tiegusanin L, (7S,8S, $R$-biar)-6,6,7,8-tetrahydro12,13-methylenedioxy-1,2,3,14-tetramethoxy-7,8dimethyldibenzo[a,c]cycloocten-9-one, and $\left(8 R, 7^{\prime} R, 8 R\right)$ 5-hydroxy-4,3',4'-trimethoxy-2,7'-cyclolignan (Xiao et al. 2010b).

Also, our team has recently conducted research on the exploration of the chemical composition of $S$. rubriflora specimens grown in Poland. Preliminary phytochemical analyses of leaf and fruit extracts using the LC-DAD method showed the presence of fourteen dibenzocyclooctadiene lignans. The total amount of dibenzocyclooctadiene lignans in leaf extracts was low $(107 \mathrm{mg} / 100 \mathrm{~g} \mathrm{DW})$, but in fruit extracts it was 6 times higher $(653 \mathrm{mg} / 100 \mathrm{~g} \mathrm{DW})$. The main compounds in fruit extracts were: deoxyschisandrin, angeloyl/tigloyl-gomisin Q and $\mathrm{H}$, schisantherin $\mathrm{A}$, benzoylgomisin $\mathrm{P}$ and $\gamma$-schisandrin [unpublished].

Recently, a lot of chemical studies on S. rubriflora have concentrated on the nortriterpenoid group. New, so far unknown, structures of nortriterpenoids have been discovered in the leaves and stems of $S$. rubriflora: rubriflorins A-J (Fig. 10), schirubridilactones $\mathrm{A}-\mathrm{F}$, and other nortriterpenoids, including lancifodilactones $\mathrm{A}, \mathrm{C}$, and $\mathrm{D}$, micrandilactones $\mathrm{A}$ and D, and henridilactones A-C (Xiao et al. 2007a, b, Xiao et al. 2010b, c). Moreover, novel highly unsaturated rearranged bisnortriterpenoids have been detected in S. rubriflora stems: rubriflordilactones A and B (Fig. 11) (Xiao et al. 2006a).

$\mathrm{Li}$ et al. (2005) reported the occurrence of specific megastigmane glycosides (the megastigmane 


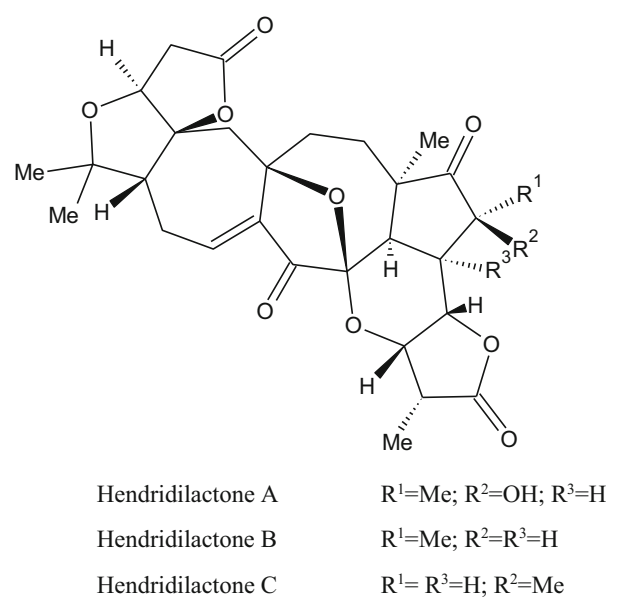

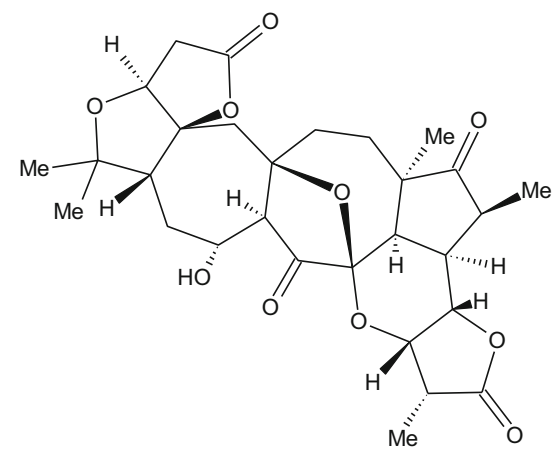

Hendridilactone D

Fig. 7 Chemical structure specific for S. henryi nortriterpenoid compounds-hendridilactones: A, B, C and D

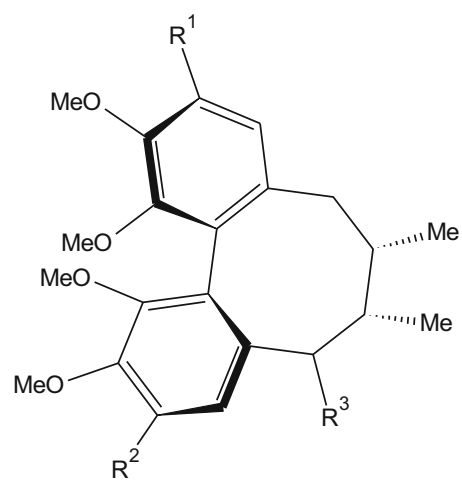

$$
\begin{array}{ll}
\text { kRubrilignan } & \mathrm{R}^{1}=\mathrm{R}^{3}=\mathrm{OMe} ; \\
\mathrm{A} & \mathrm{R}^{2}=\mathrm{AcO} \\
\text { Rubrilignan } \mathrm{B} & \mathrm{R}^{1}=\mathrm{AcO} ; \\
& \mathrm{R}^{2}=\mathrm{R}^{3}=\mathrm{OMe}
\end{array}
$$

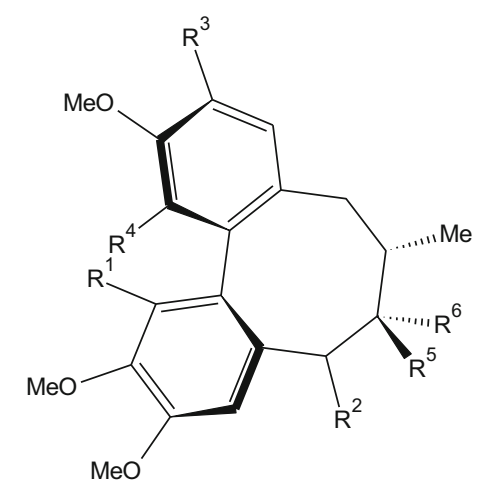

Rubrisandrin A $\quad \mathrm{R}^{1}=\mathrm{R}^{3}=\mathrm{OH} ; \mathrm{R}^{2}=\mathrm{R}^{5}=\mathrm{H} ; \mathrm{R}^{4}=\mathrm{OMe}$; $\mathrm{R}^{6}=\mathrm{Me}$

Rubrisandrin $\mathrm{B} \quad \mathrm{R}^{1}=\mathrm{R}^{4}=\mathrm{OH} ; \quad \mathrm{R}^{2}=\mathrm{R}^{5}=\mathrm{H} ; \mathrm{R}^{3}=\mathrm{OMe}$;

$\mathrm{R}^{6}=\mathrm{Me}$

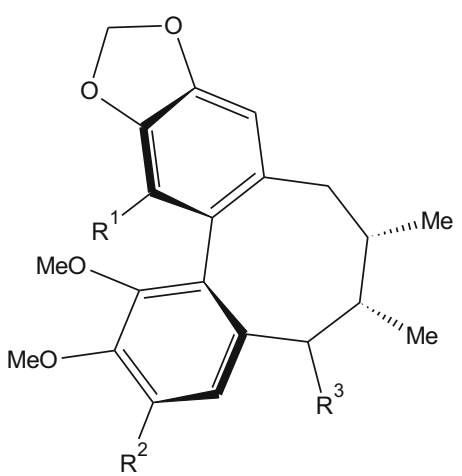

Rubrischisantherin $\mathrm{R}^{1}=\mathrm{R}^{2}=\mathrm{OMe}$; $\mathrm{R}^{3}=\mathrm{OAc}$

Fig. 8 Chemical structures of $S$. rubriflora specific derivatives of dibenzocyclooctadiene lignans: rubrilignan A and B, rubrisandrin $\mathrm{A}$ and $\mathrm{B}$, and rubschisantherin

skeleton is characterized by a benzene ring substituted on carbons 1, 5 and 6, and an aliphatic chain of four carbon atoms attached to carbon 6) in stem extracts of $S$. rubriflora, namely $(3 S, 5 R, 6 S, 9 R)$ megastigmane-3, 9-diol 3- $O$-[ $\alpha$-L-arabionfuranosyl$(1 \rightarrow 6)$ - $\beta$-D-glucopyranoside], 7-megastigmane-3-ol9-one $\quad 3-O$ - $[\alpha$-L-arabionfuranosyl- $(1 \rightarrow 6)-\beta$-D-glucopyranoside] (2), and megastigmane- $3 \alpha, 4 \beta, 9 \xi$ triol 3-O- $\beta$-D-glucopyranoside.

Among the confirmed phenolic structures in stem extracts were: one phenolic acid-glucosyringic acid, and three flavonoids: naringin, didimin (acinoside, isosakuranetin-7-O-rutinoside) and maesopsin-6-Oglucopyranoside (Li et al. 2005).

\section{The pharmacological potential}

\section{Schisandra sphenanthera}

Schisandra sphenanthera is principally used as a tonic and restorative in East-Asian countries to 


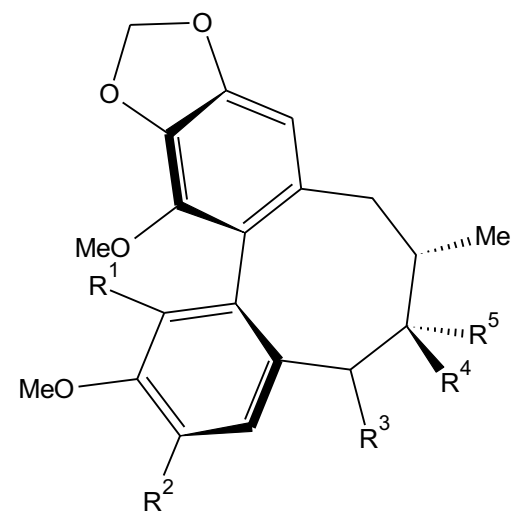

$\begin{array}{lll}\text { Schirubrin } A & \mathrm{R}^{1}=\mathrm{R}^{5}=\mathrm{OH} ; \quad \mathrm{R}^{2}=\mathrm{OMe} ; \\ & \mathrm{R}^{3}=\beta \mathrm{OAng} ; \mathrm{R}^{4}=\mathrm{Me} \\ \text { Schirubrin } \mathrm{B} & \mathrm{R}^{1}=\mathrm{R}^{5}=\mathrm{OH} ; \quad \mathrm{R}^{2}=\mathrm{OMe} ; \\ & \mathrm{R}^{3}=\beta \mathrm{OBz} ; \mathrm{R}^{4}=\mathrm{Me} \\ \text { Schirubrin C } & \mathrm{R}^{1}=\mathrm{OMe} ; \quad \mathrm{R}^{2}=\mathrm{R}^{5}=\mathrm{OH} ; \quad \mathrm{R}^{3}= \\ & \beta O A n g ; \mathrm{R}^{4}=\mathrm{Me}\end{array}$

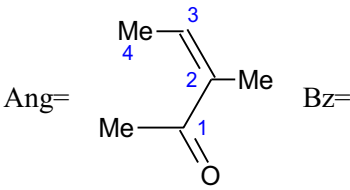

Fig. 9 Chemical structures of S. rubriflora specific derivatives of dibenzocyclooctadiene lignans: schirubrins A-D

enhance the function of the liver and other organs (Fan et al. 2014). The hepatoprotective effect is associated with antiviral action and protection from chemical hepatitis and various hepatotoxins (Zhu et al. 2000; Xie et al. 2010). What has been proven is that schisantherin A, B, C, and D, isolated from $S$. sphenanthera fruits, show good effects in lowering the glutamic-pyruvic transaminase level in the serum of patients suffering from chronic viral hepatitis. In addition to that, it was shown that schisantherin $\mathrm{E}$ and deoxyschisandrin were not effective (Liu et al. 1978).

Recently, studies performed by the Chinese team from Sun Yat-sen University in Guangzhou and based on the herb-drug interaction demonstrated the influence of $S$. sphenanthera fruit extracts on three important drugs: cyclosporine A, paclitaxel and tacrolimus.

The study on rats showed that cyclosporine A blood concentration was significantly altered by co-

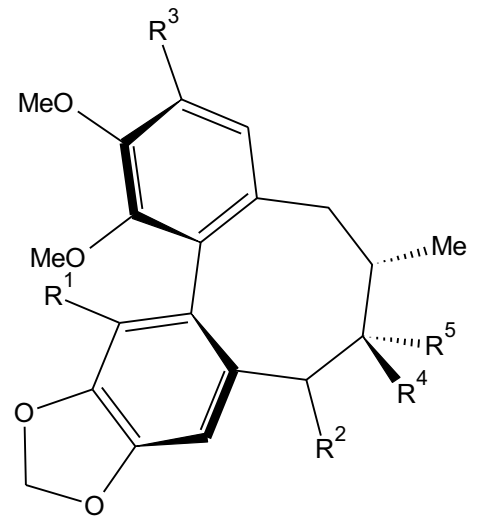

Schirubrin $\mathrm{D} \quad \mathrm{R}^{1}=\mathrm{R}^{5}=\mathrm{OH} ; \mathrm{R}^{2}=\beta \mathrm{OAng}$; $\mathrm{R}^{3}=\mathrm{OMe} ; \mathrm{R}^{4}=\mathrm{Me}$ administration of 'Wuzhi tablets' (S. sphenanthera fruit extract standardized on $7.5 \mathrm{mg}$ of schisantherin A per tablet) at a low dose of cyclosporine A (1.89 $\mathrm{mg} / \mathrm{kg}$ ), but only slightly affected when an ordinary dose of cyclosporine A $(37.8 \mathrm{mg} / \mathrm{kg})$ was administrated. The low dose of cyclosporine A might be more sensitive to associate application of CYP3A/ P-gp inhibitors or inducers (Xue et al. 2013).

With regard to co-administration of 'Wuzhi tablets' with paclitaxel, the study on rats proved significant increases of paclitaxel level in blood after oral administration $\left(\mathrm{AUC}_{0-24 \mathrm{~h}}\right.$ from 280.8 to $543.5 \mathrm{ng} / \mathrm{mL}$ ). The pharmacokinetic data for in viral paclitaxel administration with 'Wuzhi tablets' showed a relatively small but still significant increase in $\mathrm{AUC}_{0-24 \mathrm{~h}}$ (from 163.6 to $212.7 \mathrm{ng} / \mathrm{mL}$ ) and a decrease in clearance (from 3.2 to $2.2 \mathrm{~L} / \mathrm{h} / \mathrm{kg}$ ) (Jin et al. 2011; Xue et al. 2013). Summing up, the $S$. sphenanthera fruit extract significantly increased the 


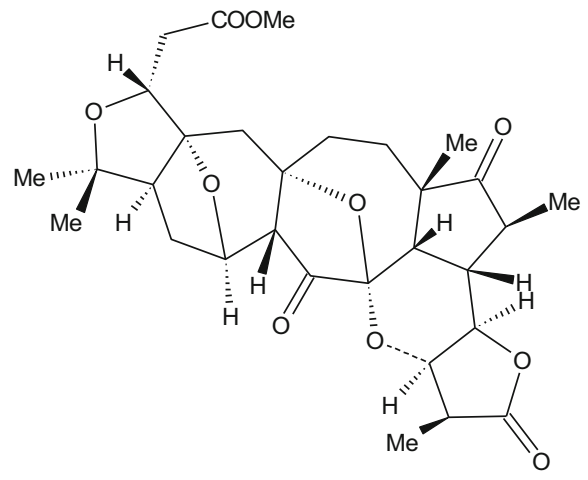

Rubriflorin A

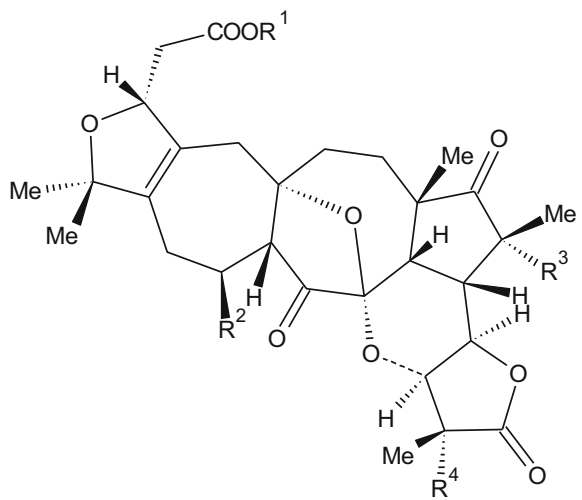

Rubriflorin B

Rubriflorin C

Rubriflorin D

$\mathrm{R}^{1}=\mathrm{Me} ; \mathrm{R}^{2}=\mathrm{R}^{3}=\mathrm{R}^{4}=\mathrm{H}$

$\mathrm{R}^{1}=\mathrm{Et} ; \mathrm{R}^{2}=\mathrm{R}^{3}=\mathrm{R}^{4}=\mathrm{H}$

Rubriflorin E

$\mathrm{R}^{1}=\mathrm{R}^{3}=\mathrm{R}^{4}=\mathrm{H} ; \mathrm{R}^{2}=\mathrm{OH}$

$\mathrm{R}^{1}=\mathrm{R}^{3}=\mathrm{R}^{4}=\mathrm{H} ; \quad \mathrm{R}^{2}=\mathrm{AcO}$;

$\mathrm{R}^{4}=\mathrm{OH}$

Rubriflorin $\mathrm{F} \quad \mathrm{R}^{1}=\mathrm{R}^{3}=\mathrm{H} ; \quad \mathrm{R}^{4}=\mathrm{AcO}$;

$\mathrm{R}^{4}=\mathrm{OH}$

Rubriflorin G

$\mathrm{R}^{\mathrm{l}}=\mathrm{Et}$;

$\mathrm{R}^{2}=\mathrm{OH}$

$\mathrm{R}^{3}=\mathrm{R}^{4}=\mathrm{H}$

Rubriflorin $\mathrm{H}$

$\mathrm{R}^{\mathrm{l}}=\mathrm{Et} ; \mathrm{R}^{2}=\mathrm{R}^{3} \mathrm{R}^{4}=\mathrm{OH}$

Rubriflorin I

$\mathrm{R}^{1}=\mathrm{Et} ; \mathrm{R}^{2}=\mathrm{R}^{3}=\mathrm{R}^{4}=\mathrm{OH}$

Rubriflorin J

$\mathrm{R}^{1}=\mathrm{Me} ; \quad \mathrm{R}^{2}=\mathrm{OH}$

$\mathrm{R}^{3}=\mathrm{R}^{4}=\mathrm{H}$

Fig. 10 Chemical structures of R. rubriflora specific nortriterpenoids: rubriflorins A-J, schirubridilactones A and B
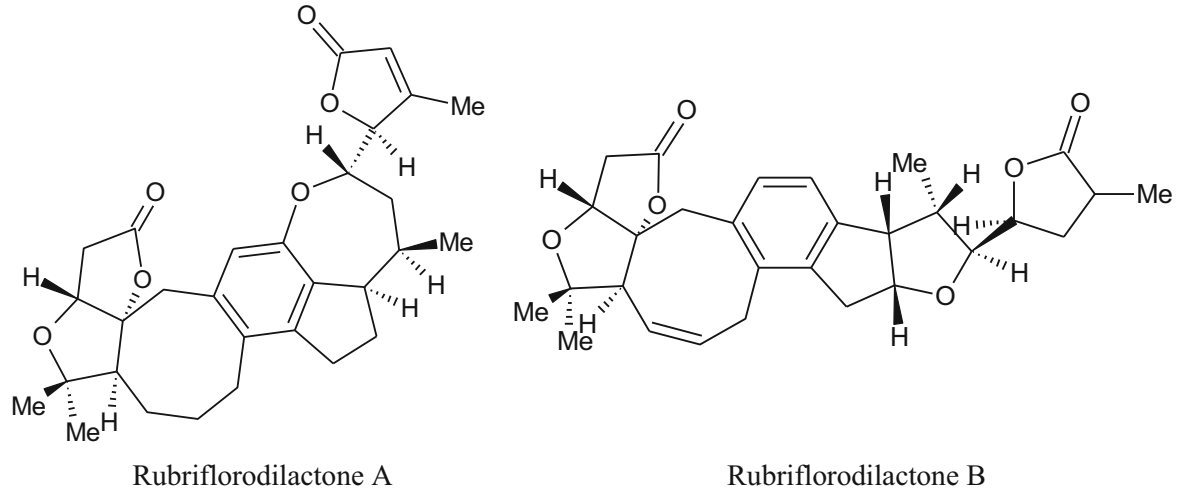

$$
\text { Rubriflorodilactone A }
$$

Rubriflorodilactone B

Fig. 11 Chemical structures of R. rubriflora specific highly unsaturated rearranged bisnortriterpenoids: rubriflordilactones A and B

concentration of paclitaxel in rat's blood, and thus increased the systemic exposure to this drug, which should be taken into consideration in clinical use (Jin et al. 2011).

The studies on co-administration of 'Wuzhi tablets' with tacrolimus in rats indicated that most of the tacrolimus tissue concentrations were slightly increased after the accompanying dose of 'Wuzhi tablets', but the whole blood concentration of tacrolimus was greatly increased (threefold after a concomitant 'Wuzhi tablets' dose) (Qin et al. 2010a). Moreover, the influence of $S$. sphenanthera fruit 
extract on absorption and first-pass intestinal and hepatic metabolism was confirmed. The mechanism of action is based on the inhibited P-gp-mediated efflux and CYP3A-mediated metabolism of tacrolimus, and the reduction in the intestinal first-pass effect by the fruit extract was the major cause of the increased tacrolimus oral bioavailability (Qin et al. 2010b).

In relation to the positive effect of $S$. sphenanthera fruit extracts on hepatocytes, the protective effect of Nan-wuweizi fruits on different drug-induced hepatotoxicity has also been studied. There has been shown a protective effect toward acetaminophen. The 'Wuzhi tablets' ( $S$. sphenanthera fruit extract standardized on $7.5 \mathrm{mg}$ of schisantherin A per tablet) prevented acetaminophen-induced liver injury by the inhibition of P450-mediated acetaminophen metabolic activation, activation of the NRF2-ARE pathway to induce detoxification and antioxidation, and regulation of p53/p21-mediated cell cycle to facilitate liver regeneration after acetaminopheninduced liver injury (Bi et al. 2013; Fan et al. 2014).

Nan-wuweizi extract also has antioxidant properties and might be useful in the prevention and treatment of hyperproliferative and inflammatory skin diseases (Huyke et al. 2007; Lu and Chen 2009). This mechanism of action is currently protected by patents (Garnier et al. 2012; Garnier and Msika 2013). Huyke et al. (Huyke et al. 2007) showed that the studied non-polar $S$. sphenanthera fruit extract obtained by $\mathrm{CO}_{2}$ extraction was the most active with a halfmaximal inhibitory concentration of $20 \mu \mathrm{g} / \mathrm{mL}$. In a cell-free enzyme inhibition assay with recombinant cyclooxygenase-2 (COX-2), this extract showed dose-dependent inhibitition of COX-2 catalysed prostaglandin $\mathrm{PGE}_{2}$ production $\left(\mathrm{IC}_{50}=0.2 \mu \mathrm{g} / \mathrm{mL}\right.$ ). It also reduced the ultraviolet-B (UVB)-induced $\mathrm{PGE}_{2}$ production $\left(\mathrm{IC}_{50}=4 \mu \mathrm{g} / \mathrm{mL}\right)$ and $\mathrm{COX}-2$ expression in HaCaT keratinocytes.

\section{Schisandra henryi}

Scientific papers describing the biological activity of $S$. henryi focus on the cytotoxic activity of this raw material (Christophe 2013).

Chen et al. (2005) tested some biological activity of compounds isolated from $S$. henryi stems. They proved the significant cytotoxic effect of gomisin $\mathrm{G}$ on leukemia and Hela cells in vitro with $\mathrm{IC}_{50}$ of $5.51 \mu \mathrm{g} / \mathrm{mL}$ toward leukemia and Hela cells. Schisantherin $\mathrm{A}$ and benzoylgomisin $\mathrm{Q}$ showed moderate cytotoxic activities on leukemia cells, with $\mathrm{IC}_{50}$ of 55.1 and $61.2 \mu \mathrm{g} / \mathrm{mL}$, respectively. Moreover, benzoylgomisin Q also showed cytotoxicity on Hela cells, with $\mathrm{IC}_{50}$ of $61.2 \mu \mathrm{g} / \mathrm{mL}$.

The studies performed on the lanostane triterpenoids isolated from $S$. henryi stems: schiprolactone $\mathrm{A}$ and $\mathrm{B}$, and schisandronic acid, have proven them to show moderate cytotoxic activity against leukemia cells in vitro, with $\mathrm{IC}_{50}$ equal: $0.0097,0.01$ and $0.0099 \mu \mathrm{mol} / \mathrm{mL}$, respectively and against Hela cells in vitro with $\mathrm{IC}_{50}$ equal: $0.097,0.1$ and $0.099 \mu \mathrm{mol} /$ $\mathrm{mL}$, respectively (Chen et al. 2003).

Moreover, henrischinins A and B-isolated from $S$. henryi leaves and stems, showed weak cytotoxicity against HL-60 cell lines with $\mathrm{IC}_{50}$ values of 16.5 and $10.5 \mu \mathrm{M}$, respectively (Xue et al. 2011).

\section{Schisandra rubriflora}

Schisandra rubriflora has long been used as a tonic remedy in Chinese folk medicine (Wu et al. 2008). As far as biological activities of $S$. rubriflora fruit extracts are concerned, until now only anti-HIV-1 property was shown by Chinese teams (Chen et al. 2006; Mu et al. 2011). For the isolated rubrilignans A and $\mathrm{B}$, a weak anti-HIV-1 activity was shown, with $\mathrm{EC}_{50}$ values of 2.26 and $1.82 \mathrm{mg} / \mathrm{mL}$, respectively (Mu et al. 2011). The inhibitory effects against HIV replication in $\mathrm{H} 9$ lymphocytes in vitro was proven for rubrisandrins A, schisanhenol, gomisin J, M1 and M2 isolated form $S$. rubriflora fruit, too. The results showed that gomisin M1 was the most potent compound, with an $\mathrm{EC}_{50}$ of less than $0.65 \mu \mathrm{M}$ (Chen et al. 2006). In connection with these studies, the first concise synthesis of 6,5,5,5-tetracyclic moiety (DEFG ring system) in rubriflordilactone $\mathrm{B}$, related to promising anti-HIV activity, has recently been achieved (Peng et al. 2015).

Additionally, it has been indicated that S. rubriflora stem extracts are effective in reducing the level of glutamic-pyruvic transaminase, which may be of use in the treatment and diagnosis of liver and bile duct diseases (Li et al. 2004a). 


\section{The potential in biotechnological studies}

Plant in vitro cultures, and the possibility of increasing the production of secondary metabolites offered by various techniques used in plant biotechnology, create opportunities for applying them in the pharmaceutical, cosmetics and food industries. Specific strategies used to increase the production of active compounds take advantage of such treatments as: selection of highly-productive cell lines, optimization of culture conditions (selection of culture medium, composition of plant growth regulators), type of culture (agar, agitated), degree of organogenesis (shoot, callus), illumination and temperature conditions, application of elicitors, or genetic transformation. In addition, the ability to provide industry with valuable raw materials and their production on a larger scale create opportunities based on the development of protocols for micropropagation of selected species. Cultivation of in vitro cultures makes it possible to control and stimulate the production of secondary metabolites. The developed micropropagation protocols ensure the obtaining of highly productive copies of medicinal plant species valuable for the pharmaceutical, cosmetics and food industries (Verpoorte et al. 2002; Walsh 2002, 2003; Ma et al. 2005; Schneider et al. 2013; Georgiev et al. 2014).

In vitro cultures of the species $S$. chinensis are the object of interest of select research centres in the world: Japanese, Czech, and Polish. To date, micropropagation protocols for this species have been developed (Březinová et al. 2010; Kohda et al. 2012; Szopa et al. 2016b, 2017b, 2018). Studies on the endogenous accumulation of secondary metabolites in S. chinensis in vitro cultures are of increasing popularity. Considerable achievements in this direction can be credited to our research team. Our studies are mainly focused on the production of dibenzocyclooctadiene lignans and phenolic acids. S. chinensis shoot cultures cultivated by us have been used to conduct tests on the optimization of culture parameters-selection of culture type, composition of culture medium, culture system and illumination conditions. In addition, the process of growing cultures in various types of bioreactors has been optimized (Szopa and Ekiert 2012, 2016, Szopa et al. 2016b, 2017b, 2018). The concentrations of lignans obtained in the in vitro grown biomass are considerable, based on ESI-MS/MS and LC-DAD assays, similar to the amounts of these compounds in the material grown in vivo. Generally, the amount of the main $S$. chinensis lignan-schisandrin $(66 \mathrm{mg} / 100 \mathrm{~g}$ DW), was 2.2 times higher in biomass extracts than in extracts from the leaves $(30 \mathrm{mg} / 100 \mathrm{~g} \mathrm{DW})$ of the parent plant, but 2 times lower than in the fruits (132 mg/100 g DW). Also, the maximum amounts of the other main lignans: gomisin A and deoxyschisandrin, were comparable with their amounts in the leaves, but 3.18 and 1.39 times lower than in the fruits, respectively (Szopa et al. 2016b).

In the light of the results obtained by our group with in vitro cultures of $S$. chinensis, other species of the Schisandra genus characterized as part of this

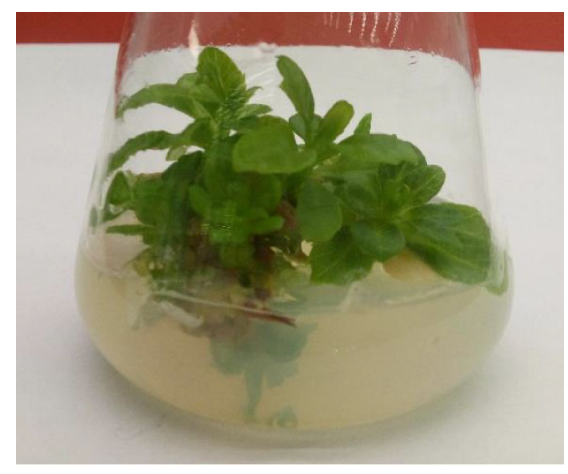

S. sphenanthera

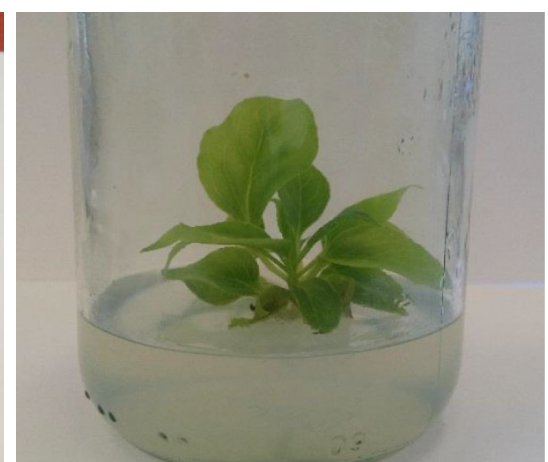

S. henryi

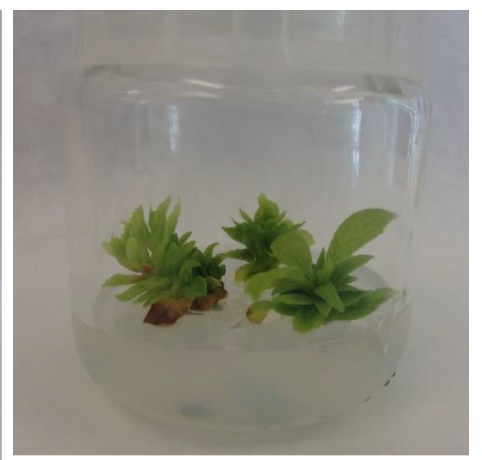

S. rubriflora

Fig. 12 The microshoot in vitro cultures of three Schisandra species: S. sphenanthera, S. henryi and S. rubriflora-agar Murashige and Skoog medium with $1 \mathrm{mg} / \mathrm{L}$ BA (6-benzyladenie) and $1 \mathrm{mg} / \mathrm{L}$ NAA (1-naphthaleneacetic acid) after 3-weeks of growth 
review are extremely interesting objects for further study. Our team has successfully initiated in vitro cultures of $S$. sphenanthera, $S$. henryi and S. rubriflora (Fig. 12) [unpublished]. The optimal culture medium for all three species proved to be the medium according to Murashige and Skoog (1962) with different combinations of plant growth regulators (from the group of cytokinins: 6-benzyladenine, thidiazuron, zeatin; and auxins: 1-naphthaleneacetic acid, indole-3-acetic acid and indole-3-butyric acid). Preliminary chromatographic analyses confirmed the presence of dibenzocyclooctadiene lignans in the in vitro cultured biomass of these species. In the near future, we plan intensive biotechnological studies for these three Schisandra species. Within the project framework, we aim to optimize the cultivation of in vitro cultures. The optimization involves aspects such as: choice of culture media, composition of plant growth regulators, duration of cultivation, and type of in vitro cultures. The major focus of this optimization is to obtain high amounts of secondary metabolites in the biomass (as well as in the growth media) of in vitro cultures. The planned biotechnological studies on new established Schisandra genus in vitro cultures are completely innovative. Based on the examination of the available literature and databases, research in this field of plant biotechnology of the Schisandra genus has not been conducted yet.

\section{Conclusions}

In the light of the presented overview of scientific data on the three species of the genus Schisandra: $S$. sphenanthera, S. henryi and S. rubriflora species have an extremely valuable potential for use not only in medicine but also in cosmetology and the food industry. They undoubtedly represent an attractive alternative to the known species $S$. chinensis which is firmly rooted in Eastern medicine. Intensive research into the chemical composition of these species has discovered new and unique compounds besides the known $S$. chinensis lignans and triterpenoids. Their biological effects, although often studied, still remain to be explored. There can be no doubt that these species are a potential source of many biologically active, valuable secondary metabolites. They should become the goal of further scientific work on these species.
In vitro cultures and finding alternative biotechnological solutions for obtaining biomass from $S$. sphenanthera, $S$. henryi and S. rubriflora seem to be a particularly valuable direction of research, which is extremely important due to the limited area of their natural occurrence and the alternative need to secure the acquisition of raw materials.

These species showed an interesting chemical composition as well as obvious biological activity and will have expanding phytotherapeutic applications in Europe. The proposed biotechnological solutions can be an alternative to importing raw materials from China.

Funding This study was funded by National Science Centre, Poland (Grant Number 2016/23/D/NZ7/01316).

\section{Compliance with ethical standards}

Conflict of interest All authors declare that they have no conflict of interest.

Open Access This article is distributed under the terms of the Creative Commons Attribution 4.0 International License (http://creativecommons.org/licenses/by/4.0/), which permits unrestricted use, distribution, and reproduction in any medium, provided you give appropriate credit to the original author(s) and the source, provide a link to the Creative Commons license, and indicate if changes were made.

\section{References}

Bensky D, Gamble A (1993) Chinese herbal medicine materia medica. Eastland Press, Vista

Bi H, Li F, Krausz KW et al (2013) Targeted metabolomics of serum acylcarnitines evaluates hepatoprotective effect of Wuzhi tablet (Schisandra sphenanthera extract) against acute acetaminophen toxicity. Evid Based Complement Altern Med. https://doi.org/10.1155/2013/985257

Březinová L, Vlašínová H, Havel L et al (2010) Validated method for bioactive lignans in Schisandra chinensis in vitro cultures using a solid phase extraction and a monolithic column application. Biomed Chromatogr 24:954-960. https://doi.org/10.1002/bmc.1391

Casarin E, Dall'Acqua S, Šmejkal K et al (2014) Molecular mechanisms of antiproliferative effects induced by Schisandra-derived dibenzocyclooctadiene lignans (+)deoxyschisandrin and (-)-gomisin $\mathrm{N}$ in human tumour cell lines. Fitoterapia 98:241-247. https://doi.org/10.1016/ j.fitote.2014.08.001

Chang J, Reiner J, Xie J (2005) Progress on the chemistry of dibenzocyclooctadiene lignans. Chem Rev 105:45814609. https://doi.org/10.1021/cr050531b

Chen Y-G, Wu Z-C, Lv Y-P et al (2003) Triterpenoids from Schisandra henryi with cytotoxic effect on leukemia and 
Hela cells in vitro. Arch Pharm Res 26:912-916. https://doi.org/10.1007/BF02980199

Chen YG, Wu ZC, Gui SH et al (2005) Lignans from Schisandra henryi with DNA cleaving activity and cytotoxic effect on leukemia and Hela cells in vitro. Fitoterapia 76:370-373. https://doi.org/10.1016/j.fitote.2005.03.012

Chen M, Kilgore N, Lee KH, Chen DF (2006) Rubrisandrins A and $\mathrm{B}$, lignans and related anti-HIV compounds from Schisandra rubriflora. J Nat Prod 69:1697-1701. https://doi.org/10.1021/np060239e

Chen Y, Zhang Y, Liu Y et al (2010) A new triterpenoid acid from Schisandra henryi. Chem Natl Compd 46:480-481

Chen Y, Tang J, Wang X et al (2012) An immunostimulatory polysaccharide (SCP-IIa) from the fruit of Schisandra chinensis (Turcz.) Baill. Int J Biol Macromol 50:844-848. https://doi.org/10.1016/j.ijbiomac.2011.11.015

Chen YC, Liaw CC, Bin Cheng Y et al (2013) Anti-liver fibrotic lignans from the fruits of Schisandra arisanensis and Schisandra sphenanthera. Bioorgan Med Chem Lett 23:880-885. https://doi.org/10.1016/j.bmcl.2012.11.040

Chinese Pharmacopoeia Commission (2005) Pharmacopoeia of the People's Republic of China. China Chemical Industry Press, Beijing

Chiu PY, Lam PY, Yan CW, Ko KM (2011) Schisandrin B protects against solar irradiation-induced oxidative injury in BJ human fibroblasts. Fitoterapia 82:682-691. https://doi.org/10.1016/j.fitote.2011.02.010

Christophe W (2013) Lead compounds from medicinal plants for the treatment of cancer, 1st edn. Elsevier, London

Connolly JD, Hill RA (2010) Triterpenoids. Nat Prod Rep 27:79-132. https://doi.org/10.1039/B808530G

Denk T, Oh IC (2005) Phylogeny of Schisandraceae based on morphological data: evidence from modern plants and the fossil record. Plant Syst Evol 256:113-145. https://doi. org/10.1007/s00606-005-0327-3

European Directorate for the Quality of Medicines (2013) Schisandra fruit. In: European Pharmacopoeia 8.0. Strasburg, p 1381

European Directorate for the Quality of Medicines (2017) Schisandra fruit. In: European Pharmacopoeia 9.0. Strasburg, p 1514

European Food Safety Authority (2010) Panel on dietetic products, nutrition and allergies 1489

Fan X, Jiang Y, Wang Y et al (2014) Wuzhi tablet (Schisandra sphenanthera extract) protects against acetaminophen-induced hepatotoxicity by inhibition of CYP-mediated bioactivation and regulation of NRF2-ARE and p53/p21 pathways. Drug Metab Dispos 42:1982-1990. https://doi. org/10.1124/dmd.114.059535

Fil'kin AM (1952) About Schizandra chinensis (historical-literary information). Aptechnojje Delo 2:46-48

Garnier S, Msika P (2013) Schisandra sphenanthera fruit extract and cosmetic, dermatological, and nutraceutical compositions comprising same (Patent)

Garnier S, Naaimi D, Baudouin C (2012) Cosmetic composition for the treatment of acne comprising a peptide extract of Schizandra (Patent)

Georgiev V, Schumann A, Pavlov A, Bley T (2014) Temporary immersion systems in plant biotechnology. Eng Life Sci 14:607-621. https://doi.org/10.1002/elsc.201300166
Gottlieb OR (1972) Chemosystematics of the Lauraceae. Phytochemistry 11:1537-1570. https://doi.org/10.1016/ 0031-9422(72)85001-5

Hancke J, Burgos R, Wikman G et al (1994) Schizandra chinensis, a potential phytodrug for recovery of sport horses. Fitoterapia 65:113-118

Hancke JL, Burgos RA, Ahumada F (1999) Schisandra chinensis (Turcz.) Baill. Fitoterapia 70:451-471. https://doi. org/10.1016/S0367-326X(99)00102-1

He F, Pu JX, Huang SX et al (2010) Schinalactone A, a new cytotoxic triterpenoid from Schisandra sphenanthera. Org Lett 12:1208-1211. https://doi.org/10.1021/o1902974j

Hernandez DE, Hancke JL, Wikman G (1988) Evaluation of the anti-ulcer and antisecretory activity of extracts of Aralia elata root and Schizandra chinensis fruit in the rat. J Ethnopharmacol 23:109-114. https://doi.org/10.1016/ 0378-8741(88)90120-1

Hu D, Yang Z, Yao X et al (2014) Dibenzocyclooctadiene lignans from Schisandra chinensis and their inhibitory activity on NO production in lipopolysaccharide-activated microglia cells. Phytochemistry 104:72-78. https://doi. org/10.1016/j.phytochem.2014.04.014

Huang SX, Bin Han Q, Lei C et al (2008) Isolation and characterization of miscellaneous terpenoids of Schisandra chinensis. Tetrahedron 64:4260-4267. https://doi.org/10. 1016/j.tet.2008.02.085

Huang HC, Lin YC, Fazary AE et al (2011) New and bioactive lignans from the fruits of Schisandra sphenanthera. Food Chem 128:348-357. https://doi.org/10.1016/j.foodchem. 2011.03.030

Huyke C, Engel K, Simon-Haarhaus B et al (2007) Composition and biological activity of different extracts from Schisandra sphenanthera and Schisandra chinensis. Planta Med 73:1116-1126. https://doi.org/10.1055/s-2007-981559

Hwang SY, Lee YJ, Lee YK et al (2009) Gomisin N isolated from Schisandra chinensis significantly induces anti-proliferative and pro-apoptotic effects in hepatic carcinoma. Mol Med Rep 2:725-732. https://doi.org/10.3892/mmr_ 00000163

Hwang D, Shin SY, Lee Y et al (2011) A compound isolated from Schisandra chinensis induces apoptosis. Bioorgan Med Chem Lett 21:6054-6057. https://doi.org/10.1016/j. bmcl.2011.08.065

Iu HL, Li-jia XU, Eng YP et al (2009) Two new lignans from Schisandra henryi. Chem Pharm Bull 57:405-407. https://doi.org/10.1248/cpb.57.405

Jiang K, Song QY, Peng SJ et al (2015) New lignans from the roots of Schisandra sphenanthera. Fitoterapia 103:63-70. https://doi.org/10.1016/j.fitote.2015.03.015

Jin J, Bi H, Hu J et al (2011) Effect of Wuzhi tablet (Schisandra sphenanthera extract) on the pharmacokinetics of paclitaxel in rats. Phyther Res 25:1250-1253. https://doi.org/10.1002/ptr.3407

Ko KM, Mak DH, Li PC et al (1995) Enhancement of hepatic glutathione regeneration capacity by a lignan-enriched extract of fructus Schisandrae in rats. Jpn J Pharmacol 69:439-442

Kochetkov NK, Khorlin A, Chizhov OS, Sheichenko VI (1961) Schizandrin-lignan of unusual structure. Tetrahedron Lett 2:730-734. https://doi.org/10.1016/S0040-4039(01)91684-3 
Kohda H, Ozaki M, Namera A (2012) Production of lignans in calluses of Schisandra chinensis. J Nat Med 66:373-376. https://doi.org/10.1007/s11418-011-0586-y

Korea Food and Drug Administration (2002) Korean Pharmacopoeia. Seoul

Li L, Ren H, Yang X et al (2004a) Rubriflorin A and B, two novel partially saturated dibenzocyclooctene lignans from Schisandra rubriflora 19 species, mostly growing in the southwestern part of the country on mountains $1500 \mathrm{~m}$. Helv Chim Acta. 87:3-7

Li L, Ren HY, Yang XD et al (2004b) Rubriflorin A and B, two novel partially saturated dibenzocyclooctene lignans from Schisandra rubriflora. Helv Chim Acta 87:2943-2947. https://doi.org/10.1002/hlca.200490265

Li R, Shen Y, Xiang W, Sun H (2004c) Four novel nortriterpenoids isolated from Schisandra henryi var. yunnanensis. Eur J Org Chem. https://doi.org/10.1002/ejoc.200300560

Li GP, Zhao JF, Tu YQ et al (2005) Chemical constituents of Schisandra rubriflora Rehd. et Wils. J Integr Plant Biol 47:362-367. https://doi.org/10.1111/j.1744-7909.2005. 00085.X

Li HM, Luo YM, Pu JX et al (2008) Four new dibenzocyclooctadiene lignans from Schisandra rubriflora. Helv Chim Acta 91:1053-1062. https://doi.org/10.1002/hlca. 200890113

Liang C, Hu J, Shi Y et al (2013) Schisphenlignans A-E: five new dibenzocyclooctadiene lignans from Schisandra sphenanthera. Chem Pharm Bull 61:96-100

Liu CS, Fang SD, Huang MF et al (1978) Studies on the active principles of Schisandra sphenanthera Rehd. et Wils. The structures of schisantherin A, B, C, D, E, and the related compounds. Sci Sin 21:483-502

Liu JS, Huang MF, Ayer WA, Nakashima TT (1984) Structure of enshicine from Schisandra henryi. Phytochemistry 23:11431145. https://doi.org/10.1016/S0031-9422(00)82627-8

Liu J-S, Tao Y, Huang M-F (1988) Studies on the constituents of Schisandra henryi. V. The structures of wulignan A1, A2, epiwulignan A1 and epischisandrone. J Chin Chem Soc 46:483-488

Liu H, Zhang J, Li X et al (2012) Chemical analysis of twelve lignans in the fruit of Schisandra sphenanthera by HPLCPAD-MS. Phytomedicine 19:1234-1241. https://doi.org/ 10.1016/j.phymed.2012.07.017

Lu Y, Chen DF (2009) Analysis of Schisandra chinensis and Schisandra sphenanthera. J Chromatogr A 1216:19801990. https://doi.org/10.1016/j.chroma.2008.09.070

Lu H, Liu GT (1991) Effect of dibenzo[a,c]cyclooctene lignans isolated from Fructus Schizandrae on lipid peroxidation and anti-oxidative enzyme activity. Chem Biol Interact 78:77-84. https://doi.org/10.1016/0009-2797(91)90104-F

Ma J, Chikwamba R, Sparrow P et al (2005) Plant-derived pharmaceuticals - the road forward. Trends Plant Sci 10:580-585. https://doi.org/10.1016/j.tplants.2005.10.009

Miao M, Gao J, Zhang G et al (2009) Effect of Schisandra chinensis polysaccharide on intracerebral acetylcholinesterase and monoamine neurotransmitters in a Dgalactose-induced aging brain mouse model. Neural Regen Res 4:687-693. https://doi.org/10.3969/j.issn. 1673-5374.2009.09.009

Mu H-X, Li X-S, Fan P et al (2011) Dibenzocyclooctadiene lignans from the fruits of Schisandra rubriflora and their
anti-HIV-1 activities. J Asian Nat Prod Res 13:393-399. https://doi.org/10.1080/10286020.2011.565748

Murashige T, Skoog F (1962) A revised medium for rapid growth and bioassays with tobacco tissue cultures. Physiol Plant 15:473-479

Opletal L, Sovová H, Bártlová M (2004) Dibenzo[a, c]cyclooctadiene lignans of the genus Schisandra: importance, isolation and determination. J Chromatogr B 812:357371. https://doi.org/10.1016/j.jchromb.2004.07.040

Panero JL, Aranda PD (1998) The family Schisandraceae: a new record for the flora of Mexico. Brittonia 50:87. https://doi.org/10.2307/2807721

Panossian A, Wikman G (2008) Pharmacology of Schisandra chinensis Bail.: an overview of Russian research and uses in medicine. J Ethnopharmacol 118:183-212. https://doi. org/10.1016/j.jep.2008.04.020

Peng Y, Duan SM, Wang YW (2015) Concise synthesis of the DEFG ring system in rubriflordilactone $\mathrm{B}$. Tetrahedron Lett 56:4509-4511. https://doi.org/10.1016/j.tetlet.2015. 05.117

Qin XL, Bi HC, Wang CX et al (2010a) Study of the effect of Wuzhi tablet (Schisandra sphenanthera extract) on tacrolimus tissue distribution in rat by liquid chromatography tandem mass spectrometry method. Biomed Chromatogr 24:399-405. https://doi.org/10.1002/bmc.1305

Qin XL, Bi HC, Wang XD et al (2010b) Mechanistic understanding of the different effects of Wuzhi tablet (Schisandra sphenanthera extract) on the absorption and first-pass intestinal and hepatic metabolism of Tacrolimus (FK506). Int J Pharm 389:114-121. https://doi.org/10. 1016/j.ijpharm.2010.01.025

Ren R, Luo GJ, Li HM et al (2009) Schisanlactone G, a new 3,4-seco-lanostane triterpenoid from Schisandra sphenanthera. Chin Chem Lett 20:601-603. https://doi. org/10.1016/j.cclet.2008.12.053

Ren R, Ci XX, Li HZ et al (2010) New dibenzocyclooctadiene lignans from Schisandra sphenanthera and their proinflammatory cytokine inhibitory activities. Zeitschrift für Naturforsch Sect B J Chem Sci 65:211-218

Saunders RMK (ed) (2000) Monograph of Schisandra (Schisandraceae). In: Systematic botany monographs. American Society of Plant Taxonomists, pp 1-146. http:// www.jstor.org/stable/25027879

Schneider M, Windbergs M, Daum N et al (2013) Crossing biological barriers for advanced drug delivery. Eur J Pharm Biopharm 84:239-241. https://doi.org/10.1016/j. ejpb.2013.03.009

Shi P, He Q, Zhang Y et al (2009) Characterisation and identification of isomeric dibenzocyclooctadiene lignans from Schisandra chinensis by high-performance liquid chromatography combined with electrospray ionisation tandem mass spectrometry. Phytochem Anal 20:197-206. https://doi.org/10.1002/pca.1115

Shi Y-M, Li X-Y, Li X-N et al (2011) Schicagenins A-C: three cagelike nortriterpenoids from leaves and stems of Schisandra chinensis. Org Lett 13:3848-3851. https://doi. org/10.1021/ol201366d

Shuwei L, Haodong C (2000) On the indications of bifendate. Advers Drug React J 2:225-228

Sun Y, Wen X, Huang H (2010) Population genetic differentiation of Schisandra chinensis and Schisandra 
sphenanthera as revealed by ISSR analysis. Biochem Syst Ecol 38:257-263. https://doi.org/10.1016/j.bse.2010.01. 005

Szopa A, Ekiert H (2012) In vitro cultures of Schisandra chinensis (Turcz.) Baill. (Chinese magnolia vine) —a potential biotechnological rich source of therapeutically important phenolic acids. Appl Biochem Biotechnol 166:1941-1948. https://doi.org/10.1007/s12010-012-9622-y

Szopa A, Ekiert H (2016) The importance of applied light quality on the production of lignans and phenolic acids in Schisandra chinensis (Turcz.) Baill. cultures in vitro. Plant Cell Tissue Organ Cult 127:115-121. https://doi. org/10.1007/s11240-016-1034-1

Szopa A, Klimek M, Ekiert H (2016a) Chinese magnolia vine (Schisandra chinensis) - therapeutic and cosmetic importance. Pol J Cosmetol 19:274-284

Szopa A, Kokotkiewicz A, Marzec-Wróblewska U et al (2016b) Accumulation of dibenzocyclooctadiene lignans in agar cultures and in stationary and agitated liquid cultures of Schisandra chinensis (Turcz.) Baill. Appl Microbiol Biotechnol 100:3965-3977. https://doi.org/10. 1007/s00253-015-7230-9

Szopa A, Ekiert R, Ekiert H (2017a) Current knowledge of Schisandra chinensis (Turcz.) Baill. (Chinese magnolia vine) as a medicinal plant species: a review on the bioactive components, pharmacological properties, analytical and biotechnological studies. Phytochem Rev 16:195-218. https://doi.org/10.1007/s11101-016-9470-4

Szopa A, Kokotkiewicz A, Luczkiewicz M, Ekiert H (2017b) Schisandra lignans production regulated by different bioreactor type. J Biotechnol 247:11-17. https://doi.org/ 10.1016/j.jbiotec.2017.02.007

Szopa A, Kokotkiewicz A, Król A et al (2018) Improved production of dibenzocyclooctadiene lignans in the elicited microshoot cultures of Schisandra chinensis (Chinese magnolia vine). Appl Microbiol Biotechnol 102:945-959. https://doi.org/10.1007/s00253-017-8640-7

Thandavarayan RA, Giridharan VV, Arumugam S et al (2015) Schisandrin B prevents doxorubicin induced cardiac dysfunction by modulation of DNA damage, oxidative stress and inflammation through inhibition of MAPK/p53 signaling. PLoS ONE 10:e0119214. https://doi.org/10. 1371/journal.pone.0119214

Umezawa T (2003) Diversity in lignan biosynthesis. Phytochem Rev 2:371-390. https://doi.org/10.1023/B:PHYT. 0000045487.02836 .32

Upton R, Graff A, Jolliffe G et al (2011) American herbal pharmacopoeia: botanical pharmacognosy-microscopic characterization of botanical medicines. CRC Press, Boca Raton

Verpoorte R, Contin A, Memelink J (2002) Biotechnology for the production of plant secondary metabolites. Phytochem Rev 1:13-25. https://doi.org/10.1023/A:1015871916833

Waiwut P, Shin M-S, Yokoyama S et al (2012) Gomisin A enhances tumor necrosis factor- $\alpha$-induced G1 cell cycle arrest via signal transducer and activator of transcription 1-mediated phosphorylation of retinoblastoma protein. Biol Pharm Bull 35:1997-2003

Walsh G (2002) Biopharmaceuticals and biotechnology medicines: an issue of nomenclature. Eur J Pharm Sci 15:135-138. https://doi.org/10.1016/S0928-0987(01)00222-6
Walsh G (2003) Pharmaceutical biotechnology products approved within the European Union. Eur J Pharm Biopharm 55:3-10. https://doi.org/10.1016/S0939-6411(02) 00165-0

Wang HJ, Chen YY (1985) Studies of lignans from Schisandra rubriflora Rhed et Wils. Acta Pharm Sin 20:832-841

Wang QY, Deng LL, Liu JJ et al (2015) Schisanhenol derivatives and their biological evaluation against tobacco mosaic virus (TMV). Fitoterapia 101:117-124. https://doi. org/10.1016/j.fitote.2015.01.006

Wei H, Sun L, Tai Z et al (2010) A simple and sensitive HPLC method for the simultaneous determination of eight bioactive components and fingerprint analysis of Schisandra sphenanthera. Anal Chim Acta 662:97-104. https://doi.org/10.1016/j.aca.2009.12.039

Whiting DA (1985) Lignans and neolignans. Nat Prod Rep 193:191-211

Whiting DA (1990) Lignans, neolignans, and related compounds. Nat Prod Rep 7:349-364. https://doi.org/10.1039/ np9900700349

World Health Organization (2007) WHO monographs on selected medicinal plants, vol 3. Fructus Schisandrae, Geneva

Wu Z, Raven P, Hong DY (2008) Flora of China, vol 7. Science Press and Missouri Botanical Garden Press, Beijing, St. Louis

Xiao W-L, Yang L-M, Gong N-B et al (2006a) Rubriflordilactones A and B, two novel bisnortriterpenoids from Schisandra rubriflora and their biological activities. Org Lett 8:991-994. https://doi.org/10.1021/o1060062f

Xiao WL, Pu JX, Chang Y et al (2006b) Sphenadilactones A and B, two novel nortriterpenoids from Schisandra sphenanthera. Org Lett 8:1475-1478. https://doi.org/10. 1021/o1060324d

Xiao WL, Pu JX, Wang RR et al (2007a) Isolation and structure elucidation of nortriterpenoids from Schisandra rubriflora. Helv Chim Acta 90:1505-1513. https://doi.org/ 10.1002/hlca.200790157

Xiao WL, Wang RR, Zhao W et al (2007b) Triterpenoids from Schisandra rubriflora. J Nat Prod 33:1056-1059. https://doi.org/10.1007/s12272-010-0508-7

Xiao WL, Yang LM, Li LM et al (2007c) Sphenalactones A-D, a new class of highly oxygenated trinortriterpenoids from Schisandra sphenanthera. Tetrahedron Lett 48:55435546. https://doi.org/10.1016/j.tetlet.2007.05.152

Xiao W-L, Li R-T, Huang S-X et al (2008a) Triterpenoids from the Schisandraceae family. Nat Prod Rep 25:871. https://doi.org/10.1039/b719905h

Xiao WL, Huang SX, Wang RR et al (2008b) Nortriterpenoids and lignans from Schisandra sphenanthera. Phytochemistry 69:2862-2866. https://doi.org/10.1016/j.phytochem. 2008.09.010

Xiao W-L, Wu Y-L, Shang S-Z et al (2010a) Four new nortriterpenoids from Schisandra lancifolia. Helv Chim Acta 93:1975-1982. https://doi.org/10.1002/hlca.201000004

Xiao W, Yang S-Y, Yang L-M et al (2010b) Chemical constituents from the leaves and stems of Schisandra rubriflora. J Nat Prod 73:221-225. https://doi.org/10. 1021/np900849y

Xiao WL, Wang RR, Zhao W et al (2010c) Anti-HIV-1 activity of lignans from the fruits of Schisandra rubriflora. Arch 
Pharm Res 33:697-701. https://doi.org/10.1007/s12272010-0508-7

Xie Y, Hao H, Kang A et al (2010) Integral pharmacokinetics of multiple lignan components in normal, $\mathrm{CCl} 4$-induced hepatic injury and hepatoprotective agents pretreated rats and correlations with hepatic injury biomarkers. J Ethnopharmacol 131:290-299. https://doi.org/10.1016/ j.jep.2010.06.038

Xue Y-B, Zhang Y-L, Yang J-H et al (2010) Nortriterpenoids and lignans from the fruit of Schisandra chinensis. Chem Pharm Bull 58:1606-1611. https://doi.org/10.1248/cpb. 58.1606

Xue YB, Yang JH, Li XN et al (2011) Henrischinins A-C: three new triterpenoids from Schisandra henryi. Org Lett 13:1564-1567. https://doi.org/10.1021/ol200283y

Xue XP, Qin XL, Xu C et al (2013) Effect of Wuzhi tablet (Schisandra sphenanthera extract) on the pharmacokinetics of cyclosporin A in rats. Phyther Res 27:12551259. https://doi.org/10.1002/ptr.4849
Yasukawa K, Ikeya Y, Mitsuhashi H et al (1992) Gomisin A inhibits tumor promotion by 12 - $O$-tetra-decanoylphorbol13 -acetate in two-stage carcinogenesis in mouse skin. Oncology 49:68-71. https://doi.org/10.1159/000227014

Zhou Y, Huang S-X, Pu J-X et al (2011) Ultra performance liquid chromatography coupled with quadrupole time-offlight mass spectrometric procedure for qualitative and quantitative analyses of nortriterpenoids and lignans in the genus Schisandra. J Pharm Biomed Anal 56:916-927. https://doi.org/10.1016/j.jpba.2011.07.045

Zhu M, Yeung RY, Lin KF, Li RC (2000) Improvement of phase I drug metabolism with Schisandra chinensis against $\mathrm{CCl} 4$ hepatotoxicity in a rat model. Planta Med 66:521-525. https://doi.org/10.1055/s-2000-11202

Zhu M, Chen XS, Wang KX (2007) Variation of the lignan content of Schisandra chinensis (Turcz.) Baill. and Schisandra sphenanthera Rehd. et Wils. Chromatographia 66:125-128. https://doi.org/10.1365/s10337-007-0261-3 